\title{
Sensitivity of boreal-summer circulation and precipitation to atmospheric aerosols in selected regions - Part 1: Africa and India
}

\author{
Y. C. Sud ${ }^{1}$, E. Wilcox ${ }^{1}$, W. K.-M. Lau ${ }^{1}$, G. K. Walker ${ }^{2}$, X.-H. Liu ${ }^{3}$, A. Nenes ${ }^{4}$, D. Lee ${ }^{5}$, K.-M. Kim ${ }^{6}$, Y. Zhou ${ }^{6}$, and \\ P. S. Bhattacharjee ${ }^{7}$ \\ ${ }^{1}$ Laboratory for Atmospheres, NASA/Goddard Space Flight Center, Greenbelt, MD, USA \\ ${ }^{2}$ SAIC/General Sciences Operation, Beltsville, MD, USA \\ ${ }^{3}$ Pacific Northwest National Laboratory, Richland, WA, USA \\ ${ }^{4}$ School of Earth and Atmospheric Sciences, Georgia Institute of Technology Atlanta, GA, USA \\ ${ }^{5}$ Seoul National University, Seoul, Korea \\ ${ }^{6} \mathrm{GEST} /$ University of Maryland, Baltimore, MD, USA \\ ${ }^{7}$ Department of Geography and GeoInformation Sciences, George Mason University, VA, USA
}

Received: 27 March 2009 - Revised: 25 June 2009 - Accepted: 18 July 2009 - Published: 23 October 2009

\begin{abstract}
Version-4 of the Goddard Earth Observing System (GEOS-4) General Circulation Model (GCM) was employed to assess the influence of potential changes in aerosols on the regional circulation, ambient temperatures, and precipitation in four selected regions: India and Africa (current paper), as well as North and South America (companion paper). Ensemble-simulations were carried out with the GCM to assess the aerosol direct and indirect effects, hereafter ADE and AIE. Each simulation was started from the NCEP-analyzed initial conditions for 1 May and was integrated through MayJune-July-August of each year: 1982-1987 to provide an ensemble set of six simulations. In the first set, called experiment (\#1), climatological aerosols were prescribed. The next two experiments (\#2 and \#3) had two sets of simulations each: one with $2 \mathrm{X}$ and other with $1 / 2 \mathrm{X}$ the climatological aerosols over each of the four selected regions. In experiment \#2, the anomaly regions were advectively restricted (AR), i.e., the large-scale prognostic fields outside the aerosol anomaly regions were prescribed while in experiment \#3, the anomaly regions were advectively Interactive (AI) as is the case in a normal GCM integrations, but with the same aerosols anomalies as in experiment \#2. Intercomparisons of circulation, diabatic heating, and precipitation difference fields showed large disparities among the AR and AI simulations, which raised serious questions about the proverbial AR assumption, commonly invoked in regional climate simulation studies. Consequently AI simulation mode was
\end{abstract}

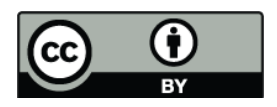

Correspondence to: Y. C. Sud (yogesh.c.sud@nasa.gov) chosen for the subsequent studies. Two more experiments (\#4 and \#5) were performed in the AI mode in which ADE and AIE were activated one at a time. The results showed that ADE and AIE work in concert to make the joint influences larger than sum of each acting alone. Moreover, the $\mathrm{ADE}$ and AIE influences were vastly different for the Indian and Africa regions, which suggest an imperative need to include them rationally in climate models. We also found that the aerosol induced increase of tropical cirrus clouds would potentially offset any cirrus thinning that may occur due to warming in response to $\mathrm{CO}_{2}$ increase.

Keywords. Atmospheric composition and structure (Aerosols and particles; Cloud physics and chemistry; Evolution of the atmosphere)

\section{Introduction}

From the sizzling hot tropics to the frigid cold high latitudes, one finds large temperature extremes that are greatly exacerbated by intrinsic natural variability of weather and climate systems and the annual cycle of solar irradiation. However, humans too exhibit the remarkable ability to endure as well as engineer their living environments to cope with weather and climate changes without much seasonal migrations. Therefore, it is rational to wonder how warming of a few degrees Celsius, as projected for the doubled $\mathrm{CO}_{2}$ environment, could be so catastrophic for human survival and why global warming is causing so much anxiety among so many people of the world? Its primary reason is

Published by Copernicus Publications on behalf of the European Geosciences Union. 
that a rise in near-surface temperatures not only melts permanent ice-cover and glaciers in the vulnerable regions of the Earth and causes the sea-level to rise and flood some of the coastal areas, but the global warming also interacts with the moist-processes of the atmosphere, modulates the circulation patterns, changes the precipitation climatologies, and can lead to water cycle hazards in several regions (IPCC, 2007) including the semi-arid. Changes in the SST patterns and associated near-surface atmospheric humidity can reorganize the Hadley and Walker cells as noted in recent GCM simulations (Held and Soden, 2006; Vecchi et al., 2006) as well as corroborated in the analyses of the 20-30 years analyzed and satellite data (e.g., $\mathrm{Hu}$ and $\mathrm{Fu}, 2007)$. A similar response of the Hadley cell was also evidenced in the warmer early Pliocene (Brierley et al., 2009). For warmer SSTs, both storms and precipitation intensities can get invigorated (Del Genio et al., 2007; Sud et al., 2008); hurricanes too can become more intense (Webster et al., 2005), and quasi-permanent changes in the global water cycle are likely to ensue (Hulme et al., 1998). Indeed, such changes have the potential of creating millions of environmental refugees (Renaud et al., 2007).

Recently, aerosol particulates have been associated with a myriad of health hazards (e.g., Knox, 2008; Whitsel et al., 2009; Smikhovich et al., 2008); however, the influence of aerosols on the distribution of radiative energy in the atmosphere and at the surface has long been recognized (Ångström, 1929). Atmospheric aerosols reduce the surface heating by the well known dimming effect by scattering and absorption of the radiant energy. According to Andreae et al. (2005), atmospheric aerosols can mitigate the global temperature rise attributable to increase of greenhouse gases by $\sim 30-50 \%$. More recently, magnitudes of aerosols radiative forcing, particularly those of soot aerosols in highly polluted regions, are found to approach that of the 20th century rise in the greenhouse-gas concentrations (Charlson et al., 1992; Shindell and Faluvegi, 2009); some studies suggest that at the regional scales, aerosol-forcing can be even larger (Ramanathan et al., 2005). Nevertheless, Lau et al. (2006) and Kim et al. (2009) showed that the manner in which aerosols influence the surface evaporation, convective precipitation, diabatic heating and circulation is quite different from that of the well-mixed greenhouse gases. They showed that anthropogenic aerosols have the potential to introduce complex anomalies in the circulation and precipitation climatology thereby creating hazardous new hot spots in the watercycle. In addition, aerosols influence the optical properties of clouds by modulating the cloud particle number concentration (CPNC) via their role as cloud condensation nuclei $(\mathrm{CCN})$ or ice nuclei (IN) that in turn affect the cloud lifetime (Albrecht, 1989) as well as alter the vertical stability of the column atmosphere (Hansen et al., 1997; Ackerman et al., 2009; Kim et al., 2009). These works suggest that the aerosol impacts need to be studied much more extensively for their effect on atmospheric dynamics that goes well be- yond a large number of in situ studies of the local influence of aerosols on clouds and radiation (e.g., Rosenfeld, 2000, and scores of others).

An ever growing human population and increasing land use also promote desertification (Hill et al., 1998). These in turn cause dust and mineral aerosols to be lifted and transported by winds. Observational data show that anthropogenic aerosols have increased sharply over Asia and Africa (Sato et al., 2003; Massie et al., 2004; Bollasina et al., 2008). Satellite data reaffirm that high aerosol amounts envelop vast regions of the tropics spanning over most regions of China to the foothills of the Himalayas and extend as far south as the Arabian Sea (Prasad et al., 2004; Girolamo et al., 2004; Ramanathan and Ramana, 2005; Chylek et al., 2006; Liu et al., 2007). One often finds clouds of aerosol over India and Southeast Asia that persist throughout the year. Ramanathan et al. (2001) coined the acronym ABC for Atmospheric Brown Clouds in tropical regions. For a comprehensive discussion of the aerosol sources and concentration, see Gradel and Kutzen (1993) and Kimberly et al. (2008). Several recent studies showed that the aerosols potentially affect weather and climate of different regions (Lohmann and Fitcher, 2001; Menon et al., 2002; Myhre et al., 2007; Nakajima et al., 2007; Takamura, 2007; Meehl et al., 2008, Lau et al., 2009a, b; Krishnamurti et al., 2009).

The influence of atmospheric aerosols has been segregated into the "so-called" direct and indirect effects. The aerosol direct effect (hereafter ADE) is caused by the optical effects of aerosols on the radiative fluxes. The key optical properties are the aerosol co-albedo representing aerosol absorption, aerosol asymmetry factor representing the angular distribution of the scattering of solar radiation, and the aerosol optical thickness. The ADE reduces the solar radiation transmitted beneath the aerosol-layer(s) by absorbing as well as reflecting the incoming solar radiation (Satheesh and Ramanathan, 2000). Thus ADE cools the surface of the Earth and decreases the surface fluxes into the planetary boundary-layer (PBL) whereby the moist static energy (MSE) of the PBL is reduced. Since the PBL top often serves as the cloud sub-layer, reduced PBL MSE leads to reduced moist-convection, a primary precipitation process in the tropics (Sud et al., 1999c). In addition, when a typical moist convective plume reaches an atmospheric layer warmed by aerosols, it encounters a temperature inversion that suddenly starts to diminish the cloud buoyancy; and, if the buoyancy vanishes, the cloud plume detrains. By absorbing the solar radiation aloft and cooling the near-surface, the aerosol layer acts as an Elevated Heat Pump (EHP), a term coined by Lau et al. (2006) for the aerosol impact on JJA precipitation over the Indian subcontinent. Kim et al. (2009) showed how ADE over West Africa and eastern Atlantic Ocean lead to a Walker-like circulation forced entirely by aerosol induced warming (cooling) of the atmospheric temperature structure over land (ocean). How do these changes effect the largescale circulation and precipitation? These questions are at the 
forefront of the ongoing modeling research (e.g., Lau et al., 2006, 2009a; Krishnamurti, 2009; Kim et al., 2009) and several observational data analyses (Huang et al, 2009; Satheesh et al., 2008; Lau and Kim, 2007; Lau et al., 2009b).

The second major impact of aerosols is the "aerosol indirect effect" (hereafter AIE). Development of AIE concepts can be traced back to the pioneering works of Towmey (1959). A comprehensive understanding of the influence of aerosols on the precipitation microphysics and cloud lifetime are relatively recent (Albercht, 1989). Overall, AIE impacts CPNC and hence the cloud particulate-size distribution, as well as the precipitation microphysics. Together they determine the cloud optical properties. Sea-salt and most sulfate aerosols serve as CCN while some fewer (e.g., black carbon and mineral dust) serve as agents of ice nucleation (IN). Recent studies show that ammonium sulfate and a few other aerosols also serve as agents of both CCN and IN. According to the first principles of aerosol nucleation as $\mathrm{CCN} / \mathrm{IN}$, larger aerosol concentrations produce more aerosol activations, which lead to more CPNC and reduced cloud particle size (Hobbs, 1999; Nenes and Seinfeld, 2003; Liu and Penner, 2005). Smaller cloud particles take much longer to coalesce into precipitation-size hydrometeors. Thus more (less) aerosols reduce (increase) precipitation efficiency and increase (decrease) the life-time of liquidclouds. More cloud particles produce higher optical thickness, higher cloud albedo, and reduced solar radiation reaching the surface; that in turn reduces the PBL MSE, which is akin to the ADE discussed earlier. Mixed phase clouds are an exception, there increasing the IN sometimes create sufficient ice clouds that grow by deposition drawing water vapor from the liquid clouds and that can initiate ice-phase precipitation.

Activated aerosols get trapped as CCN/IN inside the cloud particles that coalesce to form precipitating hydrometeors. As they fall, the precipitating hydrometeors further scavenge and collect the freely floating aerosols and slowly falling smaller hydrometeors including cloud drops. In this way, precipitation processes remove the atmospheric aerosols. Accordingly, it is a common observation that the atmosphere is less turbid after a rain-storm. Nevertheless, as long as aerosol sources are present and atmospheric transports are ample, aerosols regeneration time-scale is of the order of a few days.

Several competing factors influence the effects of aerosols on atmospheric circulation and precipitation. These include ADE, AIE, cloud-radiative forcing, precipitation efficiency and cloud life-time. ADE influences may be smaller than AIE in one scenario, but quite the opposite in another. For example, in a cloud free atmosphere, AIE is absent while aerosols are more abundant; hence all aerosol-effects are due to ADE (Liu et al., 2007). In a cloud-overcast case, there are much fewer interstitial aerosols; consequently, the AIE effectively masks ADE except when the aerosols are above the clouds (Podgorny and Ramanathan, 2001; Chand et al.,
2009). Aerosol processes also affect the vertical temperature profile of the atmosphere that in turn influences the dynamics and thermodynamics of clouds and onset of moist convection. Together, these modulate vertical distributions of mass and moisture convergence, further affecting the distribution of moist convection and cloud cover. The net outcome is a non-linear 3-dimensional response with intrinsic feedbacks. Lau et al. (2006, 2009a) assessed and explained how ADE impacts the vertical stability of the atmosphere and thereby the moist convection. Lau et al. (2009a) also showed that atmospheric heating by absorbing aerosols would strengthen the West African monsoon through the water-cycle feedbacks. The study employed the NASA GEOS-4 GCM with the same cloud physics, but without AIE. Among other recent successes of GEOS-4 GCM with AIE are realistic simulations of the behavior of winter season precipitation over northwest India due to the influence of Bombay plumes (Krishnamurti et al., 2009). The successes cited above motivated us to examine the influence of aerosol on the tropical and subtropical atmosphere as well as to determine the relative contributions of ADE and AIE on the circulation and precipitation.

\section{GEOS4 GCM and McRAS-AC}

Version-4 of the Goddard Earth Observing System (GEOS-4) atmospheric general circulation model (GCM) with aerosol cloud interaction physics was used for simulating the aerosol direct and indirect effects. GEOS-4 GCM is a grid point model with finite volume algorithms for advection (Lin, 2004; Lin and Rood, 1996). It employs a horizontal resolution of $2.0 \times 2.5$ degrees in the latitude $\times$ longitude directions and 55 levels in the vertical with hybrid co-ordinates using sigma (near surface) and pressure (above) levels. The GCM originally had the NCAR CCM3 physics (Kiehl et al., 1996, 1998); however, CCM3 cloud-physics was replaced with McRAS (Microphysics of clouds with relaxed ArakawaSchubert Scheme) following Sud et al. (2006). McRAS was formulated by Sud and Walker (1999a, b) and subsequently improved to address some specific simulation deficiencies (Sud and Walker, 2003, 2004). More recently, McRAS was upgraded to include a comprehensive AIE parameterization with a new precipitation microphysics developed for a coarse resolution model (Sud and Lee, 2007). Consequently McRAS with the aerosol cloud interaction upgrades was renamed McRAS-AC. McRAS-AC currently uses five aerosol species, viz., black carbon, sulfate, dust, organic carbon and sea salt, but its AIE-algorithms are general enough to use any number of aerosols as long as their chemical properties are known a priori. Simultaneously, the radiation modules of NCAR CCM3 were also replaced with those of Chou and Suarez $(1994,1999)$ that use Chou et al. (1998) cloud overlapping assumptions. The ADE is invoked through the optical properties of aerosols prescribed as externally mixed 


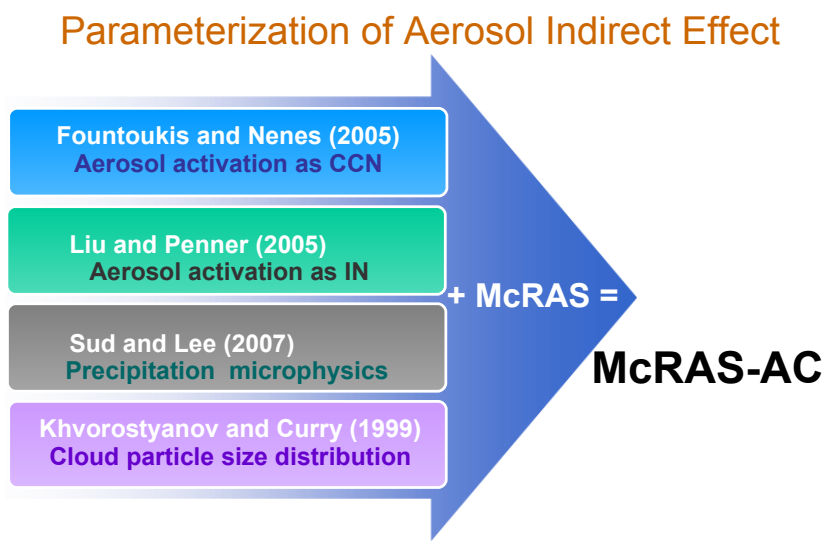

Fig. 1. Schematic Representation of the four modules of aerosol nucleation for cloud formation, precipitation microphysics, and effective radius of cloud particles for computing the aerosol-indirect effects or AIE in McRAS-AC.

species. The aerosol data are in the form of monthly aerosol fields simulated with the Georgia Institute of TechnologyGoddard Global Ozone Chemistry Aerosol Radiation and Transport (GOCART) model (Chin et al., 2002) that was forced with available aerosol emission data and analyzed wind fields for advection (Ginoux et al., 2001; Nakajima, 2002). The data has been extensively validated against the satellite and other in situ observations (Ginoux et al., 2001; Nakajima, 2002; Chin et al., 2004). The single scattering albedo and asymmetry factor of aerosols are a function of speciation, particle size, and ambient humidity. The GOCART aerosol data has five aerosol-species. Latitude height distribution of aerosol optical thickness for different aerosol species is shown in Kim et al. (2006). For AIE, the internally mixed monthly-mean aerosol climatologies of the Model for Integrated Research on Atmospheric Global Exchanges modeling system (MIRAGE) were used (Easter et al., 2004). The monthly aerosols data was linearly interpolated to provide daily data for each aerosol at each GCM grid cell. The AIE subroutines bundle of McRAS-AC is shown in Fig. 1. It consists of four sub-models comprising of i) Fountoukis and Nenes (2005) aerosol activation for liquid-clouds, ii) Liu and Penner (2005) heterogeneous and homogeneous nucleation for ice-cloud particles, iii) Sud and Lee (2007) precipitation microphysics adapted from Seifert and Beheng (2001) for a coarse resolution GCM, and iv) Khvorostyanov and Curry (1999a, b) parameterization of cloud particle effective radii. The AIE parameterization solves for CPNC, cloud optical properties via the effective radius of cloud particles and cloud mass fractions.

\section{Simulation experiments}

Five sets of simulation experiments were conducted. Each simulation was initialized with NCEP analysis data (Kalnay

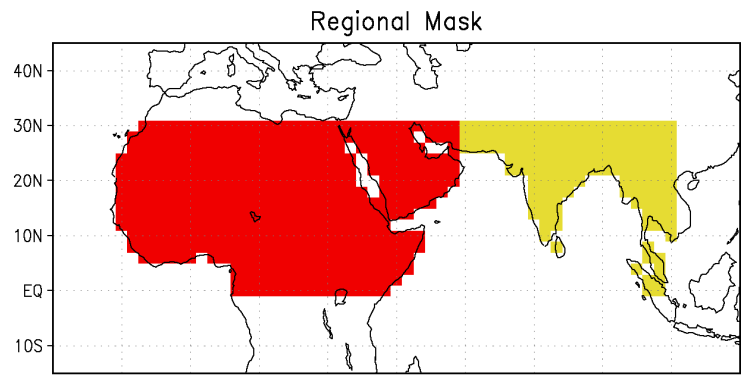

Column Aerosol Optical Depth (GOCART)

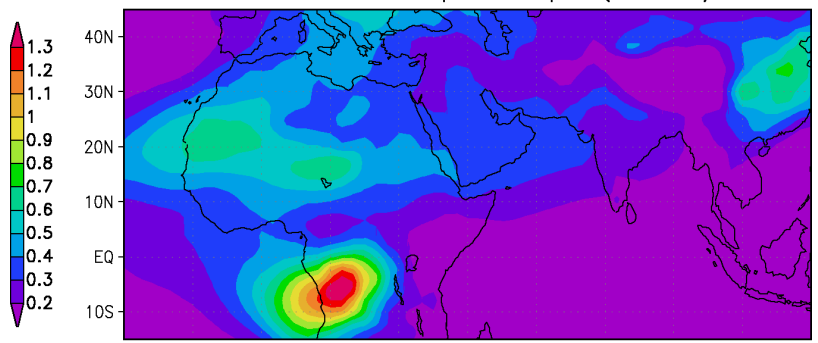

PBL CCN (\# $\left.\mathrm{mm}^{-3}\right)$ MIRAGE

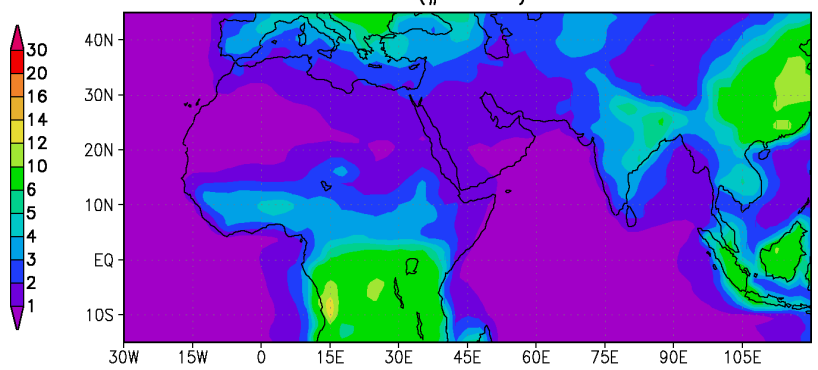

Fig. 2. Top Panel gives the locations of the four aerosol anomaly regions; only the changes over Africa and India are analyzed in this paper. The middle panel has column optical depth that produces $\mathrm{ADE}$ and the bottom panel gives maximum available CCNs for AIE.

et al., 1996) interpolated to the GEOS4 GCM grid for 1 May for each of the six simulated years: 1982 through 1987. All simulations were integrated to 31 August of the simulated year to provide data for June-July-August (JJA); the first month (1-31 May) of integration was ignored as a period of initial adjustment to the imposed aerosol anomalies and intrinsic model biases. All simulations used the prescribed SSTs based on the analyzed data produced by the Hadley Center (Reynold et al., 2002).

Recent increases in the concentration of tropical aerosols are a consequence of anthropogenic activity, viz., increasing biomass burning, fossil fuel usage, and industrial development. It is happening at a disconcerting rate in many countries in subtropical Africa, Indian subcontinent, and southeast Asia. In this study, we focused on the two selected regions: Africa and India even though four anomaly regions were prescribed as shown in the top panel of Fig. 2. The other two regions are analyzed in a companion paper (Wilcox et al., 2009). These regions can be expected to yield large year-toyear aerosol-variations in response to anthropogenic activity 
Table 1. Synopsis of simulation experiments.

\begin{tabular}{ccccc}
\hline Experiment\# & $\begin{array}{c}\text { Aerosol anomaly in } \\
\text { selected regions: } \\
\begin{array}{c}2 \mathrm{X} \text { or } 1 \mathrm{X} \text { or } 1 / 2 \mathrm{X} \\
\text { of climatological values }\end{array}\end{array}$ & $\begin{array}{c}\text { Aerosol direct } \\
\text { effect (ADE) } \\
\text { On/Off }\end{array}$ & $\begin{array}{c}\text { Aerosol indirect } \\
\text { effect (AIE) } \\
\text { On/Off }\end{array}$ & $\begin{array}{c}\text { Advectively restricted } \\
\text { or interactive, } \\
\text { i.e., AR or AI }\end{array}$ \\
\hline 1 & $1 \mathrm{X}$ & on & on & AI \\
$2 \mathrm{a}$ & $2 \mathrm{X}$ & on & on & AR \\
$2 \mathrm{~b}$ & $1 / 2 \mathrm{X}$ & on & on & AR \\
$3 \mathrm{a}$ & $2 \mathrm{X}$ & on & on & AI \\
$3 \mathrm{~b}$ & $1 / 2 \mathrm{X}$ & on & on & AI \\
$4 \mathrm{a}$ & $2 \mathrm{X}$ & on & off & AI \\
$4 \mathrm{~b}$ & $1 / 2 \mathrm{X}$ & on & off & AI \\
$5 \mathrm{a}$ & $2 \mathrm{X}$ & off & on & AI \\
$5 \mathrm{~b}$ & $1 / 2 \mathrm{X}$ & off & on & AI \\
\hline
\end{tabular}

with its sporadic variations as well as the weekly cycles (Bell et al., 2008). In fact the aerosol pollution levels in majority of the regions could get worse if anthropogenic activity continues to grow unabated; alternatively, it can get better with more stringent controls and regulations (George et al., 2008). The lower two panels of Fig. 2 give an overview of the aerosol optical thickness over the selected regions of Africa and India, which represents a broad measure of column integrated aerosol mass concentration, and CCN in the PBL. A factor of two increase and/or decrease in the aerosol mass concentration was adopted for the sensitivity simulations of the study. These aerosol-anomalies are rather extreme; nevertheless they are plausible, perhaps defensible too, because observations show a 6-fold increase in fossil fuel related $\mathrm{SO}_{2}$ and black carbon since 1930 (Ramanathan et al., 2005).

The simulation experiments are listed in Table 1. The first experiment was a set of six baseline simulations with climatological aerosols taken from GOCART data for externally mixed and MIRAGE data for internally mixed aerosols with both ADE and AIE turned on. It has an ensemble of six GCM simulations each of which started on 1 May and was integrated through 31 August for each of the six simulated years: 1982-1987. In the next two sets of experiments (\#2 \& \#3), aerosols were assumed to be two times $(2 \mathrm{X})$ and half times $(1 / 2 \mathrm{X})$ the aerosol climatology in each of the four aerosolanomaly regions broadly called Africa and India, and North and South America (Top panel, Fig. 2). These two experiments were used to assess the JJA response to advectively restricted dynamics (AR) versus advectively interactive dynamics (AI) with identically prescribed aerosol-forcings. In AR, the prognostic fields, viz., zonal and meridional winds, temperature, specific humidity, and cloud mass-fraction and specific cloud-liquid water were prescribed at the boundaries of the aerosol anomaly regions every six hours from the corresponding baseline simulations. The circulation and precipitation anomalies in the chosen regions showed that the biases introduced due to the AR assumption, which is often invoked in regional simulations with high resolution, were too large to ignore. Finally, two more experiments \# 4 and \#5 were conducted by repeating experiment \#3 with aerosol changes $(2 \mathrm{X}$ or $1 / 2 \mathrm{X})$ for $\mathrm{ADE}$ and AIE turned on one at a time. These experiments helped to distinguish between the direct and indirect effects of aerosols

\section{Results}

For ADE, aerosols interact with both shortwave and longwave radiation. The dust aerosols in our simulations had a single scattering albedo $(\omega)$ of 0.94 as opposed to Kim et al. (2006) study in which $\omega$ was 0.88 that assumes significant black carbon coating of dust. In more recent observations, $\omega$ for dust over highly polluted regions is close to 0.88 , but the value of 0.94 may be more relevant to large regions involving huge amounts of Saharan dust. The single scattering albedo has a strong effect on the strength of the elevated heat source and its influence on circulation and precipitation as an EHP. We examined the regional influences of aerosol-perturbations in advectively restricted (AR) simulations vis-a-vis the corresponding advectively interactive (AI) simulations. The comparison suggested the AI methodology for assessing the regional impacts of aerosols on climate. We also compared the influences of ADE and AIE, separately as well as jointly, using the simulation-experiments outlined in Sect. 3.

\subsection{Advectively restricted versus advectively interactive simulations}

The changes in precipitation, moisture convergence, and precipitable water in the atmosphere due to aerosol anomaly ( $2 \mathrm{X}$ minus $1 / 2 \mathrm{X}$ ) for advectively restricted (AR) environment (experiment\#2) and advectively interactive (AI) environment 

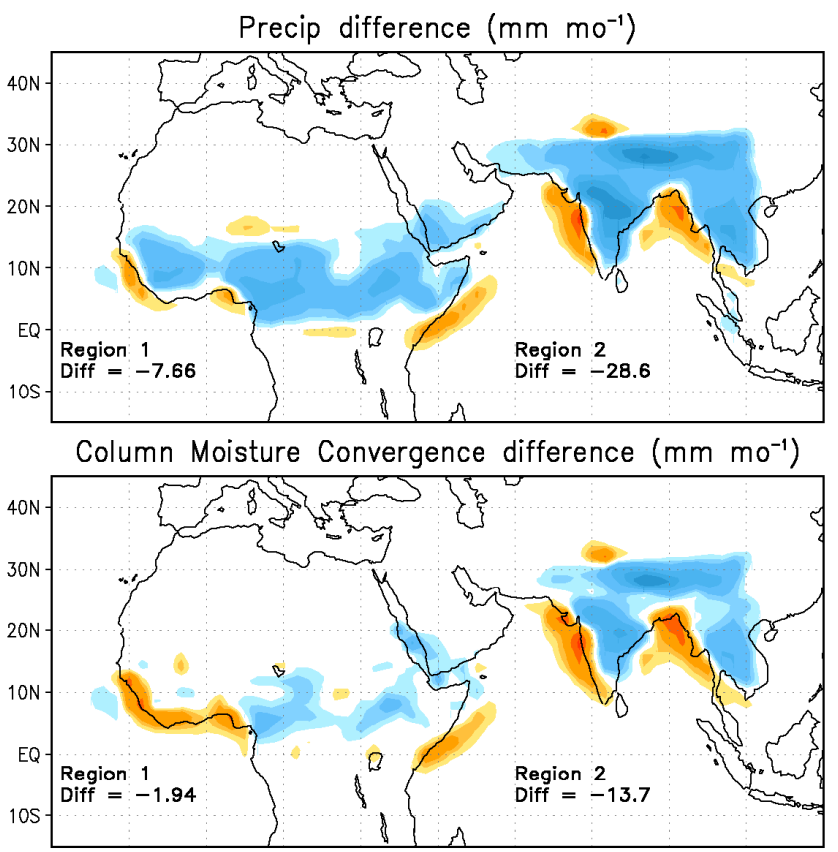

Total Precipitable Water difference $(\mathrm{mm})$

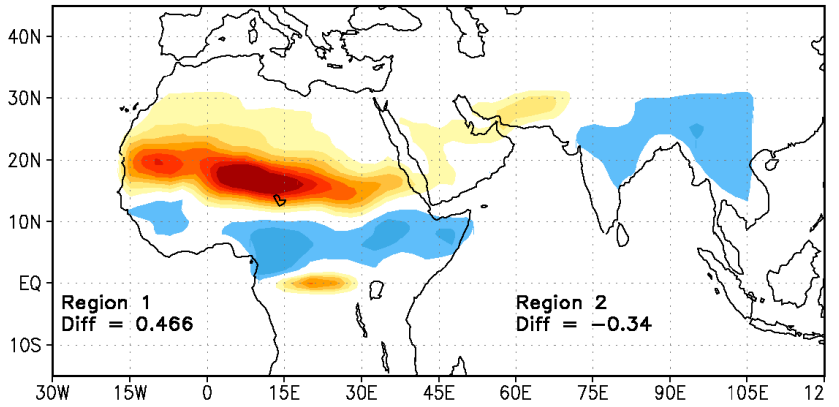

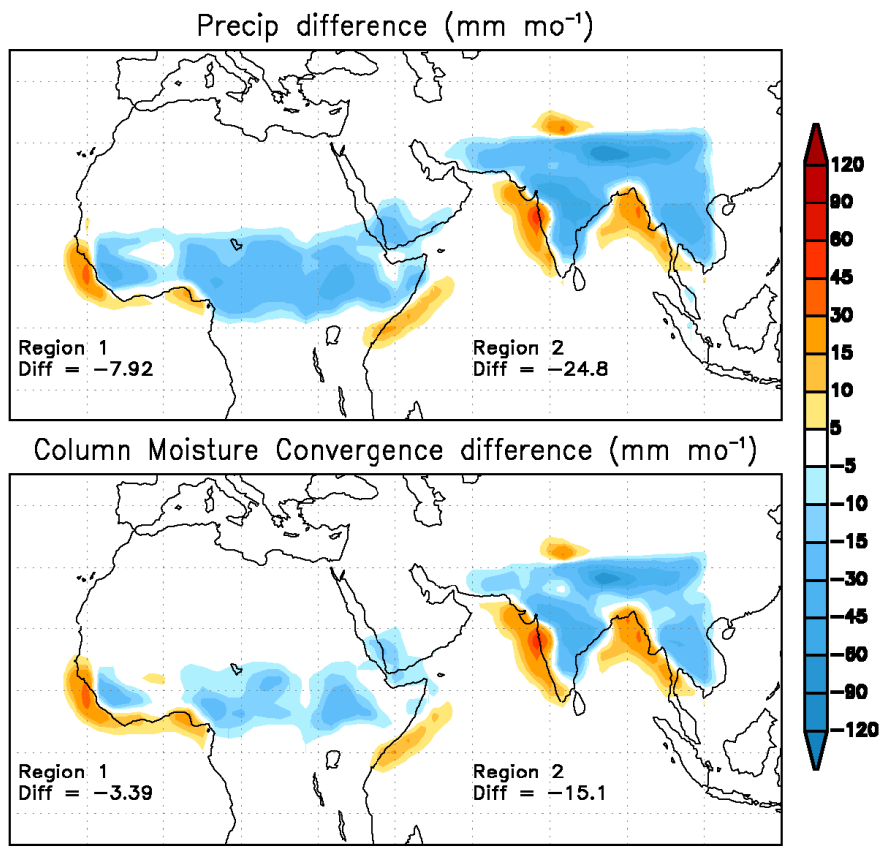

Total Precipitable Water difference $(\mathrm{mm})$

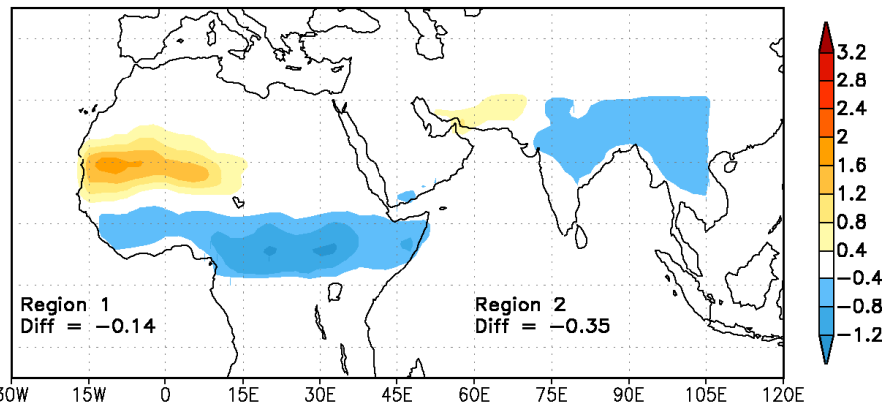

Fig. 3a. $2 \mathrm{X}$ minus $1 / 2 \mathrm{X}$ aerosol anomaly effects viewed as differences in precipitation (top), column moisture convergence (middle) and precipitable water (bottom) in AR simulations with both ADE and AIE effects (left) and only AIE (right) turned on.

(experiment \#3) are shown in Fig. 3. The differences for AR (Fig. 3a) appear only over the aerosol-anomaly regions (see Fig. 2) because all the prognostic forcing fields outside the anomaly regions were prescribed. Doubling the aerosols reduced the precipitation and moisture convergence almost everywhere except at the boundaries of the aerosol-anomaly regions. This is a consequence of the aerosol-induced radiative cooling, which yields moisture divergence from regions of reduced diabatic heating. Typically, for regions of strong moist-convection and cloud-cover, but without a high concentration of aerosols, the AIE dominates the ADE, which features strongly in the total outcome as seen in the top panel of Region 2 (Fig. 3a, b). This result is consistent with Lohmann and Feichter (2001). In the AR simulations, the differences in column moisture convergence between the combined ADE and AIE cases versus the AIE only cases were much smaller because the prognostic fields, particularly the moisture flux transports, outside the boxed regions were virtually the same, i.e., prescribed from the baseline simulations. This caused some spurious moisture convergence with excessive precipitation at the boundaries of the experimental regions that bore the brunt of the reduction of moisture flux convergence inside the aerosol anomaly regions. To determine if AR simulations can isolate the ADE and AIE effects, simulation sets of experiment \#2 were repeated with AIE alone (not shown in Table 1). Similarity between Fig. 3a and $\mathrm{c}$ shows that the aerosol anomaly regions are totally overwhelmed by the large-scale forcing rendering the simulations unfit for even distinguishing between the AIE and ADE on rainfall. This further confirms the inability of the AR simulations to address the local climate change problems. The corresponding AI simulations show much larger differences in the precipitable water associated with more cloud water in the northern latitudes (Fig. 3b, left panels). This is consistent with suppressed convection and reduced precipitation in the anomaly regions. The corresponding precipitation, moisture 

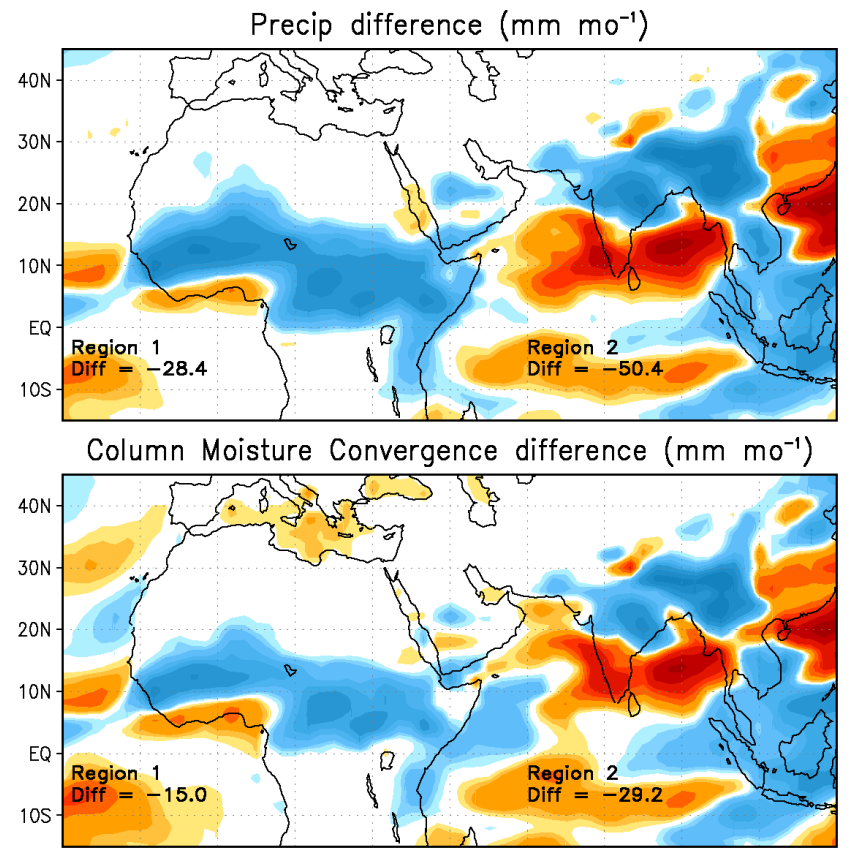

Total Precipitable Water difference $(\mathrm{mm})$

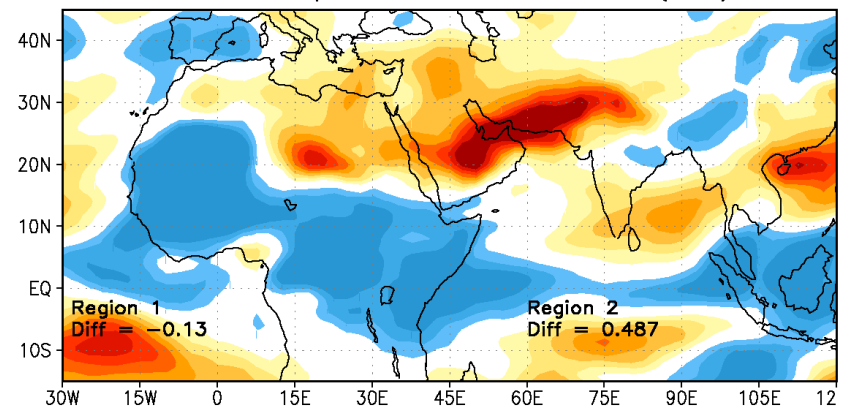

Fig. 3b. Like Fig. 3a but for the AI simulations.

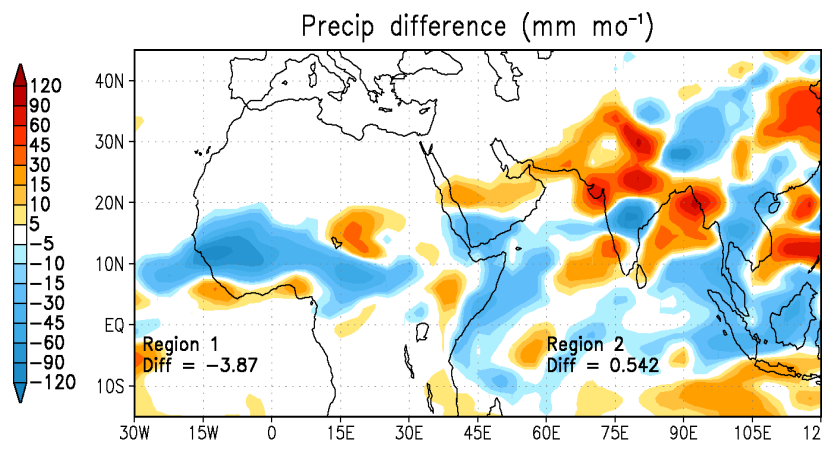

Fig. 3c. $2 \mathrm{X}$ minus $1 / 2 \mathrm{X}$ aerosol anomaly effects on differences in precipitation due to ADE only in the AI simulations.

convergence and precipitable water patterns are quite different in simulations with only AIE made active (Fig. 3b, right panels).

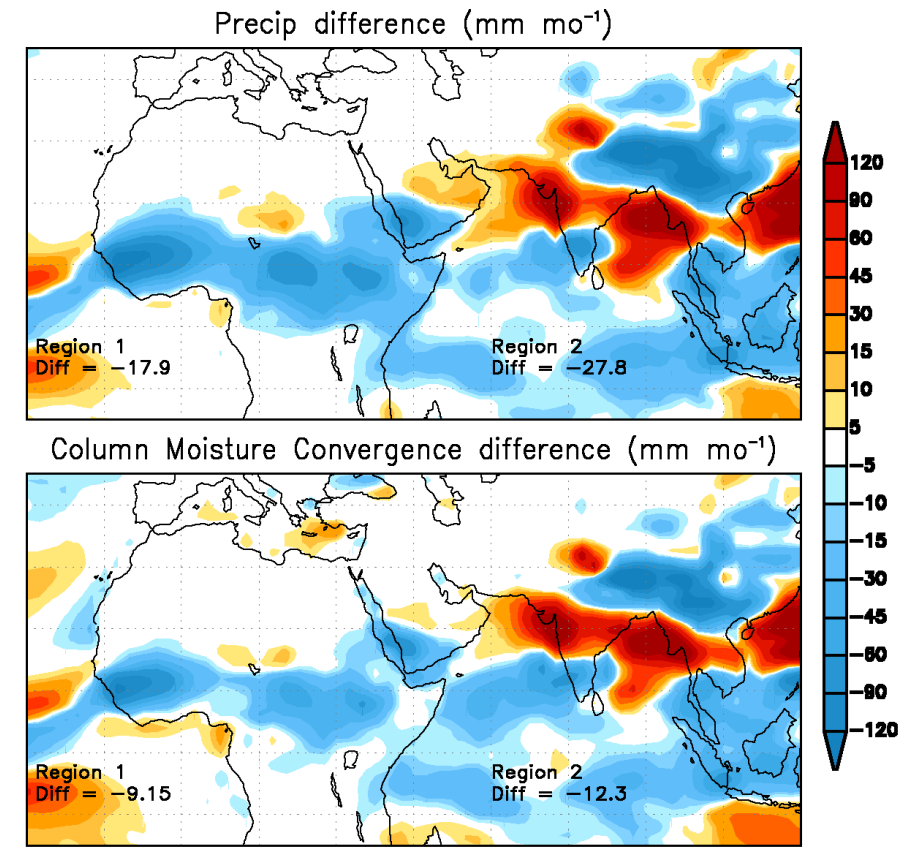

Total Precipitable Water difference $(\mathrm{mm})$

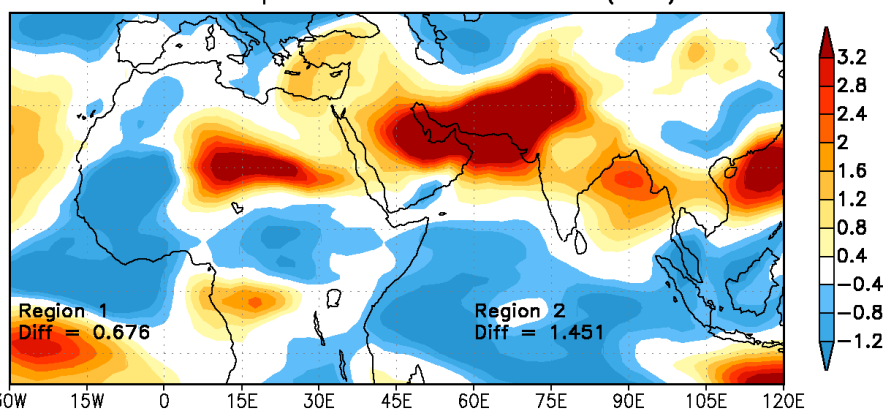

Indeed there is no similarity between the climate responses of aerosols in experiments $2 \& 3$, The stark differences among them not only appear at the boundaries of aerosol anomaly regions, but are present even in the interiors of the regions. The spurious circulation patterns in the AR vis-a-vis AI modes of assessment were evident in the $10 \mathrm{~m}$ wind vector differences as well (Fig. 4a, b). Moreover, the AI simulations showed a strong feedback effect of aerosols on the global circulation and precipitation, which is debarred in the AR simulations. Moreover, large circulation anomalies in the AI case can be seen well outside of the aerosol anomaly regions in the $700 \mathrm{hPa}$ and $300 \mathrm{hPa}$ humidity fields and radiative forcing fields at the surface and top of the atmosphere (see Sect. 4.2 for details). Such differences suggest that regional simulation studies designed to assess the response to aerosols deploying constrained dynamics at the boundaries of the anomaly regions are unable to capture the appropriate circulation and precipitation anomalies associated with changes in aerosol forcing. One can safely generalize that 
Table 2. Energy and water substances fluxes for regions $1 / 2$ based on simulation experiments 3, 4 and 5 .

\begin{tabular}{lcccc}
\hline $\begin{array}{l}\text { Difference fields (2X minus } \\
1 / 2 \mathrm{X} \text { ) aerosol simulations }\end{array}$ & $\begin{array}{c}\text { ADE \& AIE both } \\
\text { interactive Region 1/2 }\end{array}$ & $\begin{array}{c}\text { ADE only \& AIE } \\
\text { unchanged Region 1/2 }\end{array}$ & $\begin{array}{c}\text { AIE only \& ADE } \\
\text { unchanged Region 1/2 }\end{array}$ & $\begin{array}{c}\text { Non-linear inter-actions by } \\
\text { diff. Region } 1 / 2\end{array}$ \\
\hline Precipitation $\mathrm{mm} / \mathrm{mon}$ & $-28.4 /-50.4$ & $-3.9 /+0.5$ & $-17.9 /-27.8$ & $-6.6 /-23.1$ \\
Evaporation $\mathrm{mm} / \mathrm{mon}$ & $-13.4 /-20.4$ & $-3.4 /-2.6$ & $-8.7 /-15.5$ & $+1.3 /-2.3$ \\
Convergence $\mathrm{mm} / \mathrm{mon}^{-2}$ & $-15.0 /-29.2$ & $-0.5 /+3.0$ & $-9.2 /-12.3$ & $-5.7 /-20.9$ \\
Sensible heat flux W m & $-12.4 /-9.1$ & $-8.3 /-4.8$ & $-5.0 /-9.4$ & $-0.9 /+5.1$ \\
Latent heat flux W m ${ }^{-2}$ & $-12.3 /-19.3$ & $-3.2 /-2.5$ & $-8.1 /-14.4$ & $-1.0 /-2.4$ \\
TOA Shortwave $\mathrm{W} \mathrm{m}^{-2}$ & $-21.8 /-27.4$ & $-5.8 /-3.5$ & $-18.0 /-30.9$ & $+2.0 /+7.0$ \\
TOA longwave $\mathrm{W} \mathrm{m}^{-2}$ & $-18.1 /-12.3$ & $-3.5 /-3.2$ & $-21.5 /-16.3$ & $+6.9 /+7.2$ \\
TOA net radtn. $\mathrm{W} \mathrm{m}^{-2}$ & $-3.70 /-15.0$ & $-2.3 /-0.2$ & $3.5 /-14.5$ & $-4.7 /-0.3$ \\
Surface shortwave W m ${ }^{-2}$ & $-34.8 /-34.1$ & $-19.0 /-10.8$ & $-17.8 /-30.8$ & $+2.0 /+8.5$ \\
Surface longwave $\mathrm{W} \mathrm{m}^{-2}$ & $-9.9 /-5.5$ & $-7.3 /-3.1$ & $-4.5 /-6.4$ & $+2.9 /+4.0$ \\
Surface net radtn. $\mathrm{W} \mathrm{m}^{-2}$ & $-24.9 /-28.6$ & $-11.6 /-7.7$ & $-13.3 /-24.3$ & $-0.0 /+3.4$ \\
\hline
\end{tabular}

limited area simulations for cases in which regional-scale circulation changes also interact and affect the large-scale fields will produce a spurious outcome.

\subsection{Moist processes in aerosol anomaly experiments}

Hereafter, we will deal with only the advectively interactive (AI) simulations. Table 2 shows regional moisture and energy flux anomalies for $2 \mathrm{X}$ minus $1 / 2 \mathrm{X}$ aerosol anomaly simulations. Column 2 shows the results for the control case in which both AIE and ADE work together; Column 3 and Column 4 show their individual effects in each simulation experiment in which only one aerosol effect (ADE or AIE) is turned on while the other is turned off. The last column shows the differences, Column 2 minus the sum of Columns 3 and 4, which reflects the sum of non-linear interaction plus the outcome of random bias due to intrinsic variability of the model. However, the later is small on the scale of regional averages because of the large aerosol anomalies. Some inherent details of the corresponding regional differences can be seen in the relevant figures.

\subsubsection{Water cycle anomalies}

One goal of our research is to isolate the effects of ADE and AIE on clouds, cloud-radiative forcing, large-scale circulation and precipitation. Over Africa, the net influence of AIE and ADE was to reduce the precipitation by 17.9 and $3.87 \mathrm{~mm} / \mathrm{month}$ respectively, and the precipitation reduction was $28.4 \mathrm{~mm} / \mathrm{month}$ when acting together. The corresponding reductions in precipitation over Indian region are 27.8 and $0.5 \mathrm{~mm} / \mathrm{month}$, and $50.4 \mathrm{~mm} / \mathrm{month}$ when acting together. In both regions the ADE and AIE interact so as to exacerbate the precipitation reduction. Larger AIE influences over the Indian region is reasonable because the cloudiness is high while the aerosol concentrations are lesser than those of tropical Africa. The moisture convergences are also correspondingly reduced but only about half as much as the precipitation. The rest is a consequence of reduced evaporation neglecting small changes in atmospheric water storages as water vapor and cloud water. Indeed, with only the ADE turned on, there was an increase in precipitation over northern India extending to the foothills of Himalayas together with some reduction in the middle part of the country with virtually no change in the region-wide precipitation. This feature of ADE response is consistent with EHP mechanisms discovered by Lau et al. (2006) whereby radiative heating of the lower troposphere over the Indo-Gangetic plain enhances convection over northern India. The results of our simulations are qualitatively consistent with the Lau et al. (2006) findings even though the structure and distribution of the imposed aerosol anomalies were significantly different in these studies. The column moisture convergence differences are consistent with the precipitation anomaly difference to further underscore the role of circulation and surface evaporation changes as equal contributors to precipitation changes. The bottom panel of Fig. $3 \mathrm{~b}$ shows larger precipitable water in AIE-only experiments as a consequence of suppressed convection, which is evident in northern latitudes in both types of simulations suggesting suppression of convection even with higher relative humidity at 700 as well as $300 \mathrm{hPa}$ (Fig. 9). We are unable to explain how the precipitation in both ADE and AIE simulations increased in the northern plains, while it actually reduced in the coupled ADE and AIE simulations with a significant change in the precipitation pattern over India. The precipitation anomalies in ADE, and both ADE and AIE simulations were statistically significant at $99 \%$ confidence level over central and north India but not for the AIE (not shown). This also explains why the precipitation in AIE simulations over India does not align with the other two cases. Lack of statistical significance suggests how the mean precipitation in AIE is the primary cause of large values of non-linear interactions (by difference), seen in the last column of Table 2 . 

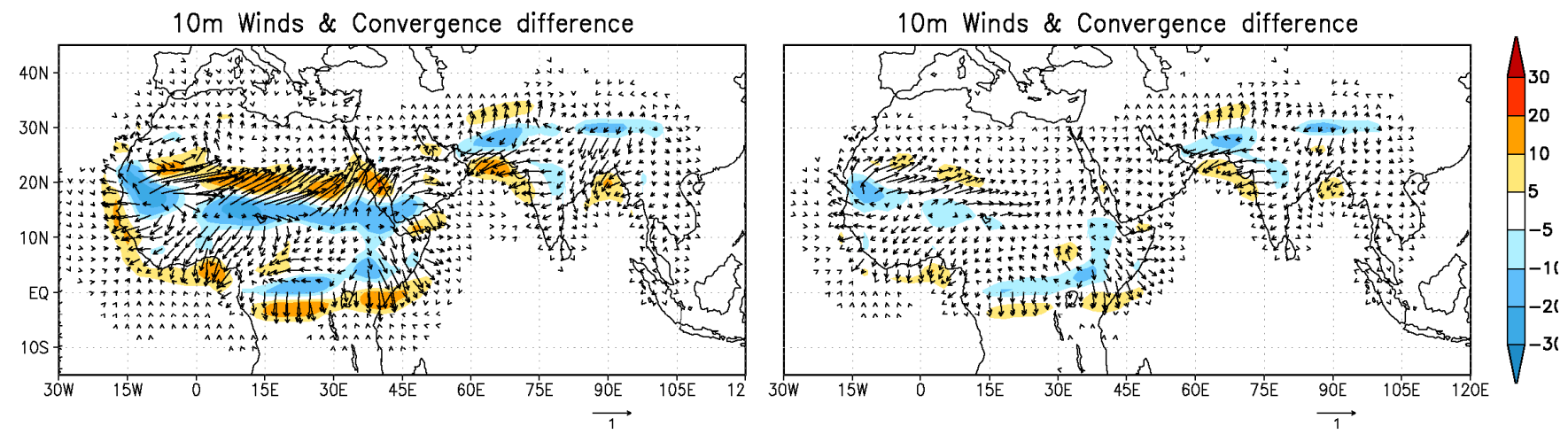

Fig. 4a. $2 \mathrm{X}$ minus $1 / 2 \mathrm{X}$ aerosol anomaly effects on wind vector differences and convergences in $10^{-7} \mathrm{~s}^{-1}$ (color shading in the background) in AR simulations with both ADE and AIE effects (left) and only AIE (right) turned on.

\subsubsection{Evaporation and sensible heat fluxes}

The sum of the changes in evaporation and sensible heat fluxes essentially equal the changes in the net surface radiation almost everywhere over land. This is valid for averages over Africa (Regions 1) and India (Region 2). The African region includes dry deserts to the north and wet rainy areas to the south, which roughly divide the region into half dry and half wet (see Fig. 5). Accordingly, the influences of aerosols on the surface fluxes of sensible and latent heat are also similar and consistent (Fig. 5; also Table 2). The Indian region has more wet than dry areas; it shows much larger decreases in the evaporation as compared to the sensible heat flux. However, both surface fluxes are reduced over land in unison with reduced net radiation, whereas the sensible heat flux changes in the surrounding ocean are comparatively small. The increase in evaporation over the Indian Ocean is large even though the aerosol perturbations were limited to the land, therefore the evaporation increase is primarily the response to circulation changes (note also that the SSTs are prescribed in these simulations). It is a consequence of the large change in the surface winds (Fig. 4). The net weakening of the monsoonal circulation causes anomalous north easterlies (evident in surface winds, a feature of winter circulation) to produce more evaporation into the drier air (Fig. 4b). The change is of the order of $0.5 \mathrm{~mm} \mathrm{~d}^{-1}$ (or $15 \mathrm{~W} \mathrm{~m}^{-2}$ ).

\subsubsection{Surface shortwave radiation anomalies}

Net surface shortwave radiative forcing differences due to aerosols anomalies (2X minus $1 / 2 \mathrm{X}$ ) are primarily limited to the anomaly regions and correspond well with the reduction of net shortwave absorbed at the surface. However, there is some spread of the radiative anomalies outside the aerosol anomaly regions as a result of changes in cloud cover, as well as moisture and cloud advection (Fig. 6, left panels). Figure 2 shows that the African region has much larger aerosol loading, particularly north of the Sahel. Accordingly, the model simulated reductions in the surface shortwave radia-

\section{Sfc Wind difference $\left(\mathrm{m} \mathrm{s}^{-1}\right)$}

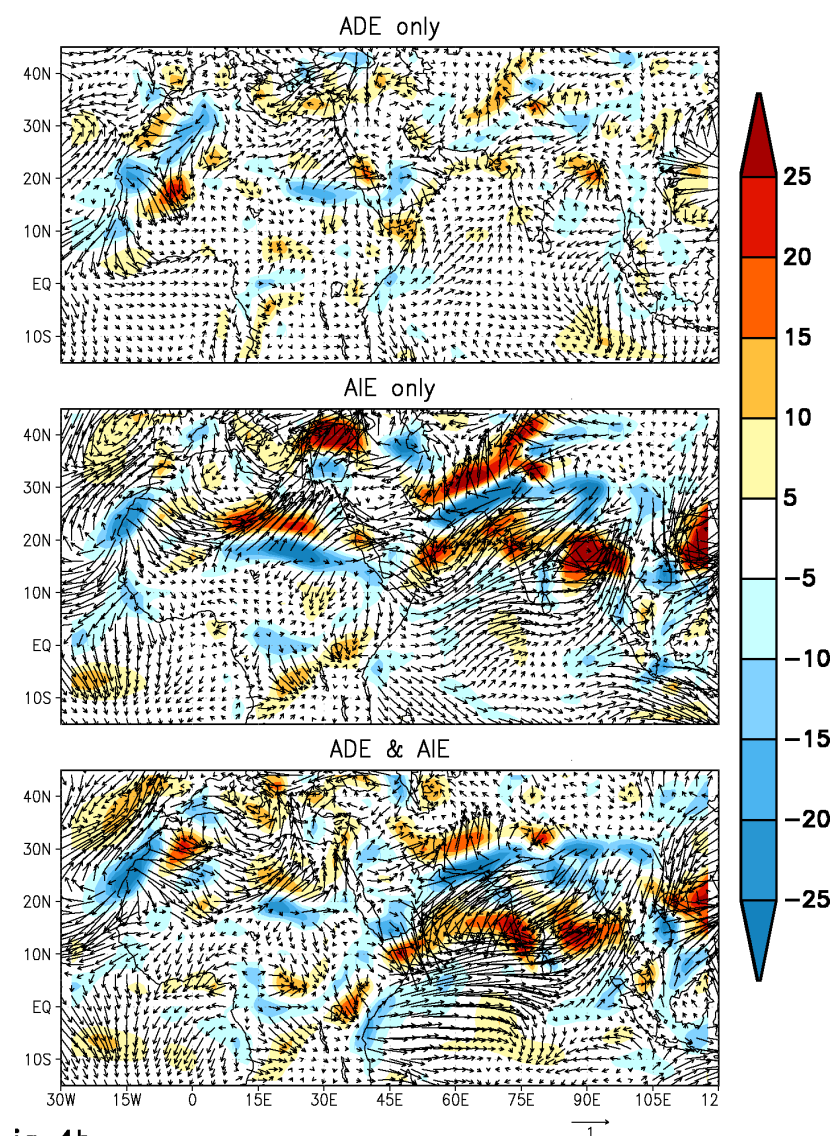

Fig. 4b. $2 X$ minus $1 / 2 X$ aerosol anomaly effects on wind vector differences and convergences (background color shading) in AI simulations with only ADE (top), only AIE (middle) and both AIE and ADE effects (left) turned on.

tion were $19.0 \mathrm{~W} \mathrm{~m}^{-2}$ due to the ADE, $17.8 \mathrm{~W} \mathrm{~m}^{-2}$ due to the AIE, and $34.8 \mathrm{~W} \mathrm{~m}^{-2}$ due to both the AIE and ADE. This represents roughly an equal contribution by ADE and 


\section{Sensible Heat Flux difference $\left(W \mathrm{~m}^{-2}\right)$}

\section{Latent Heat Flux difference $\left(W \mathrm{~m}^{-2}\right)$}
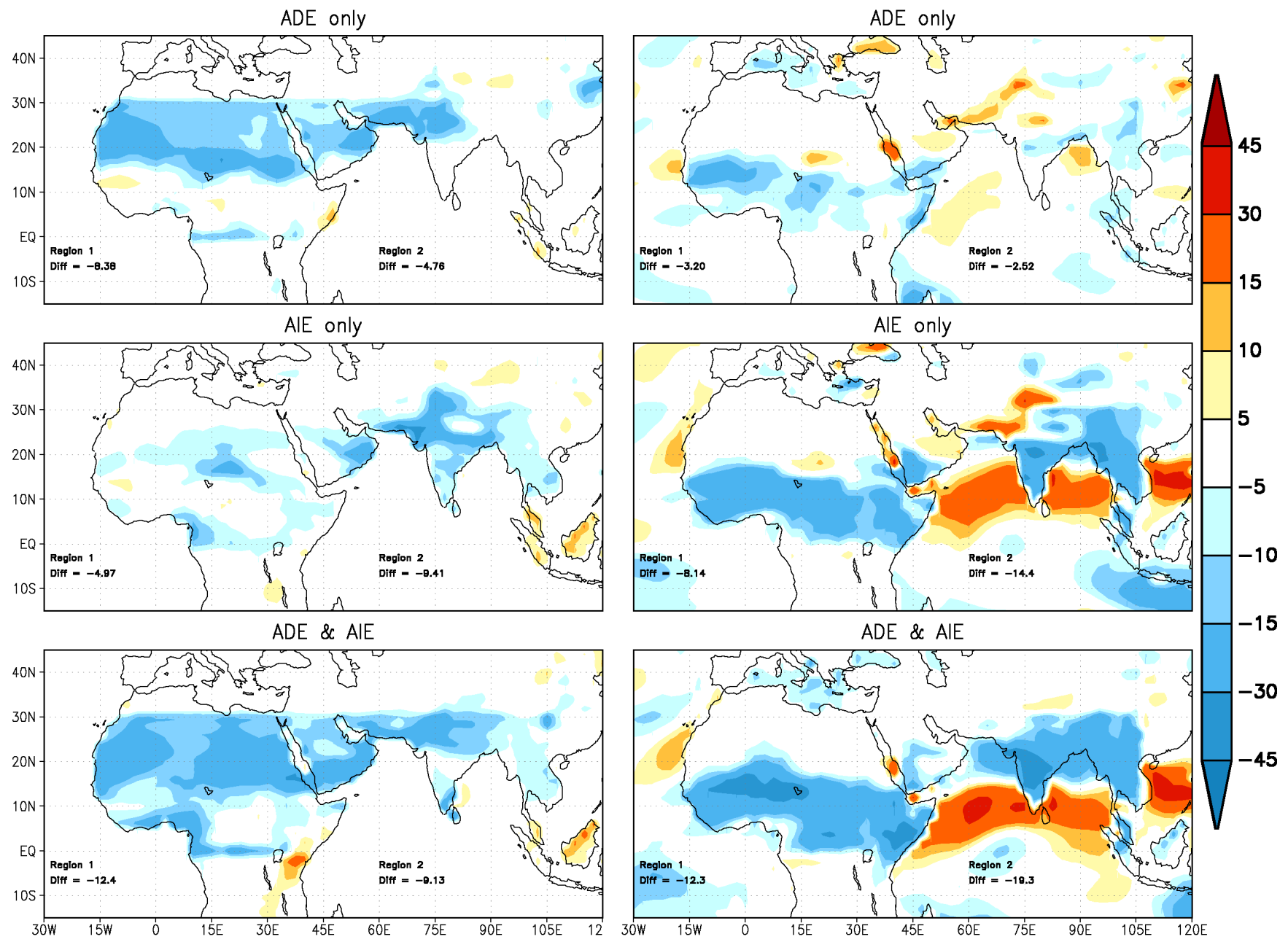

Fig. 5. Fluxes of sensible (left) and latent heat (right) for ADE (top), AIE (middle) and ADE plus AIE (bottom) panels in W $\mathrm{m}^{-2}$ for $2 X$ minus $1 / 2 \mathrm{X}$ aerosol anomaly in the earmarked regions (Fig. 2) in AI mode.

AIE in response to the reduction of net shortwave at the surface. However, the corresponding ADE and AIE reductions for India are $10.8 \mathrm{~W} \mathrm{~m}^{-2}$ and $30.8 \mathrm{~W} \mathrm{~m}^{-2}$, respectively, with the joint reduction of $34.1 \mathrm{~W} \mathrm{~m}^{-2}$ (see Table 2). This is very different from that for North Africa. First the aerosol optical thicknesses over India were smaller and so were its direct effects or ADEs. However, the monsoon season cloudiness is comparatively large and so is the corresponding AIE. Moreover, in a cloudy region AIE masks the ADE as is evident in the combined case. Why then the combined effect of all aerosols is so similar over Africa and India? This has to do with the overall constraint of shortwave heating. In the Tropics, the thermal and geopotential height gradients cannot be maintained because of weak Coriolis force. Therefore, regions of low (high) sea-level pressures correspond to warmer (colder) air columns, which result in rising (sinking) motions to increase (reduce) cloudiness and thereby produce a planetary albedo feedback in such a way that both regions receive about the same diabatic heating. This leads to similar overall planetary albedos and therefore similar short- and long-wave radiation absorption. Thus tropical clouds work like a thermostat and balance the solar forcing of the tropical regions so to get roughly similar diabatic heating over Africa and India. This is particularly true for Boreal summer because in the Boreal winter, solar heating, affected by surface albedo under relatively clear skies and adiabatic heating by subsidence regulate the temperature of the atmospheric column. The dynamic adjustments to temperature gradients at the aerosol-level are naturally invoked through EHP (Lau et al., 2006). The response is similar to that at the surface in the presence of geopotential-height gradients. The Indian monsoon season has large cloudiness in JJA with relatively small ADE due to significant aerosols removal by nucleation and scavenging. Consequently, the AIE effect over India 


\section{Sfc Net SW difference $\left(W \mathrm{~m}^{-2}\right)$}
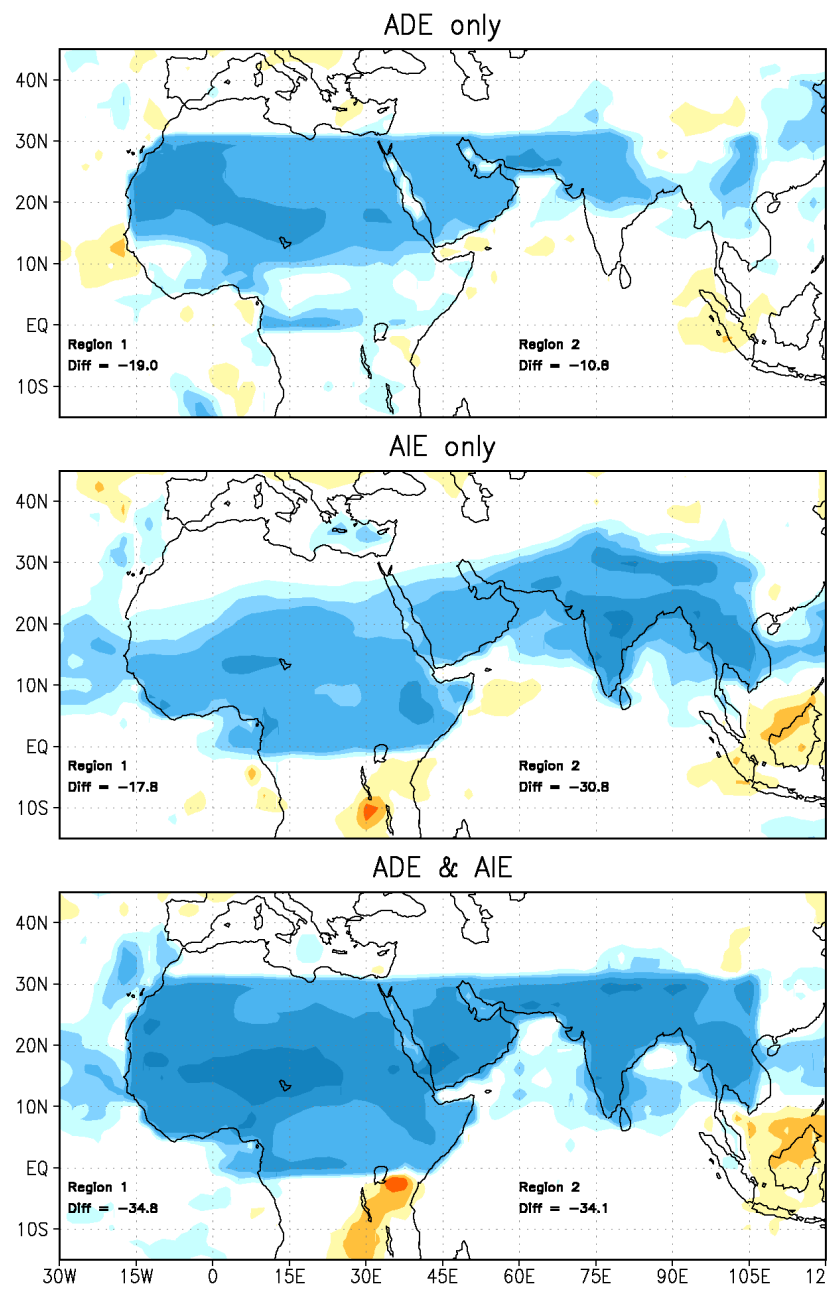

TOA Net SW difference $\left(W \mathrm{~m}^{-2}\right)$

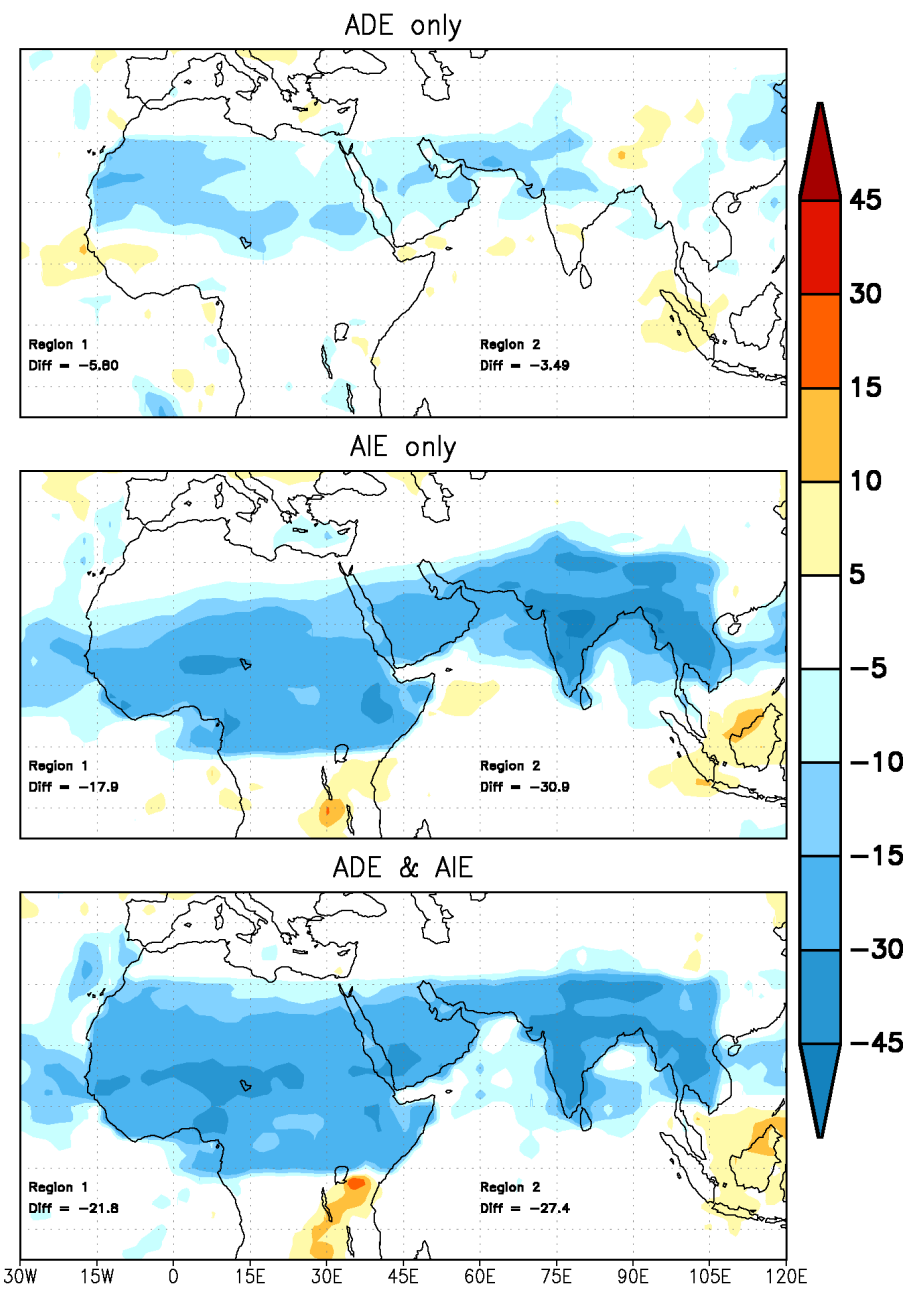

Fig. 6. Same as Fig. 5 but for fluxes of net shortwave in $\mathrm{W} \mathrm{m}^{-2}$ at the Surface (left) TOA (right) taken as positive downwards.

dominates the net solar forcing (Fig. 6). Thus, JJA clouds get adjusted to yield roughly similar planetary albedos and energy balance(s) over tropical land regions. Whereas the regional precipitation distribution is determined by the cloudscale dynamics, the energy budget including the condensation heating and thermal advection must equalize so as to yield similar net heating per unit mass of all the tropical air columns. Lack of geopotential height gradients in the tropics also lessen changes in the dry static energy by horizontal advection; therefore the remaining diabatic heating processes align to make the net energy received by the Earth Atmosphere system to remain similar over tropical land that has very little surface-energy storage as compared to the tropical oceans.

\subsubsection{Shortwave radiation anomalies TOA}

The net shortwave at the top of the atmosphere (positive downwards) is shown in the right panels of Fig. 6. ADE and AIE anomalies reduce shortwave absorption by the Earth atmosphere system and cause more shortwave reflection into space. Again, the influence of ADE is much smaller than the AIE, which suggests that an increase in clouds and cloud optical thickness dominates the outcome particularly over India where aerosol optical thicknesses were comparatively lesser. Altogether, both ADE and AIE reduce the shortwave absorbed by the earth atmosphere system. This must equal the shortwave absorbed at the surface shown in the left panels with small changes in the shortwave absorbed in the atmosphere. The change in absorption is essentially an aerosol effect because the clouds do not absorb much. Hence over Africa, a $21.8 \mathrm{~W} \mathrm{~m}^{-2}$ shortwave decrease at TOA plus $13.0 \mathrm{~W} \mathrm{~m}^{-2}$ increase in absorption by the aerosols (not 


\section{Sfc Net LW difference $\left(W \mathrm{~m}^{-2}\right)$}
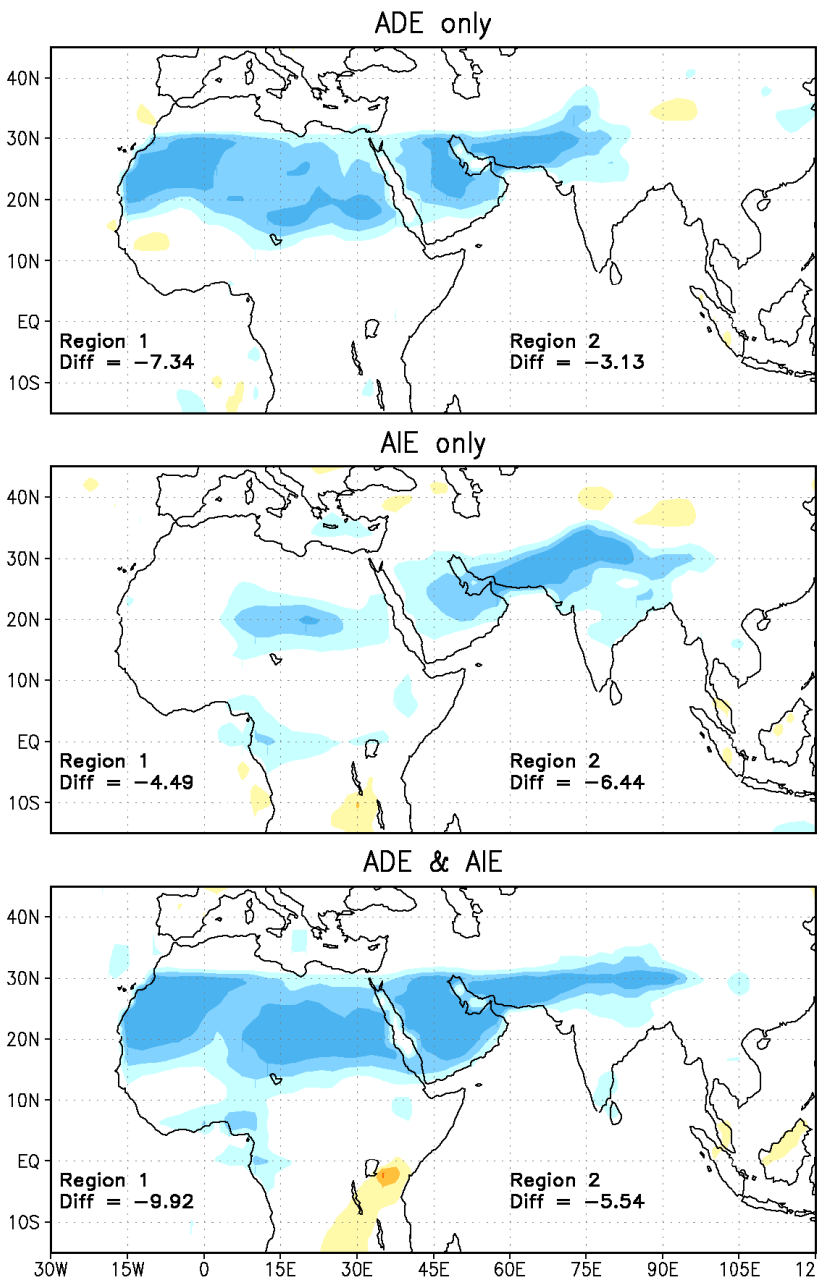

\section{TOA Net LW difference $\left(W \mathrm{~m}^{-2}\right)$}

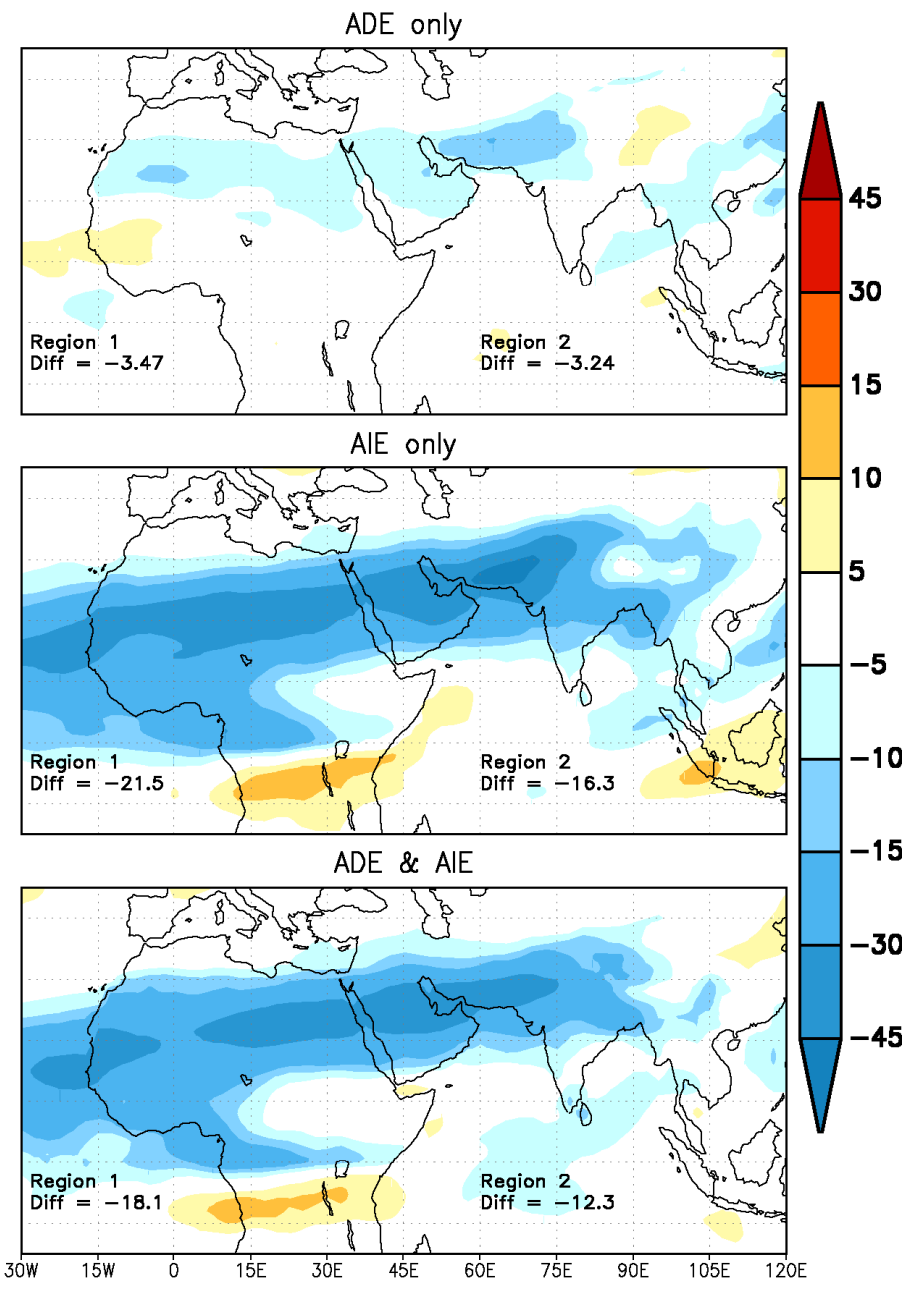

Fig. 7a. Same as Fig. 6 but for fluxes of net longwave in $\mathrm{W} \mathrm{m}^{-2}$ at the surface (left) TOA (right).

shown) amounts to $34.8 \mathrm{~W} \mathrm{~m}^{-2}$ reduction in shortwave absorbed at the surface. A similar budget analysis for India shows a $27.4 \mathrm{~W} \mathrm{~m}^{-2}$ reflection at TOA plus $6.7 \mathrm{~W} \mathrm{~m}^{-2}$ absorption essentially by aerosols (not shown) that equals $34.1 \mathrm{~W} \mathrm{~m}^{-2}$ reduction in shortwave absorbed at the surface. Despite much more carbonaceous aerosols over India, the aerosol absorption over India is only half of that over Africa that has huge Saharan dust load. Shortwave cooling at the surface for simulations with AIE plus ADE is less than the sum of the cooling for the two simulations with AIE and ADE applied separately. The leading cause of this difference (shown in the last column of Table 2 is an outcome of non-linear interactions) is that the AIE increases the cloud cover and reduces the clear-sky that contributes the bulk of the ADE when the two effects are combined. Therefore, in the ADE plus AIE simulations, the ADE contribution is lesser than that of the ADE-only simulations. The other fields for ADE and AIE are given in Fig. 6 and Table 2. The dif- ferences for AIE alone are pretty similar for the surface and TOA shortwave. In other words the surface absorption deficit is due to increased reflection at the top. For ADE anomalies, there are small differences and those are attributable to the aerosol absorption.

\subsubsection{Surface and TOA longwave radiation anomalies}

Corresponding to lesser solar radiation absorbed at the surface, the net outgoing longwave at the surface (Fig. 7a) as well as the surface fluxes of heat and water vapor (Fig. 5) were reduced also; in fact, the reductions are roughly proportional (Fig. 7a; bottom panels). In the net surface longwave over Africa, the ADE reduction is larger than that of the AIE while its converse happens over India. We also know that high level cirrus clouds can reduce the longwave escaping at the top. Thus an increase of cirrus clouds over northern Africa (Fig. 7b) caused by the AIE produced the biggest 
High-level Cloud Fraction difference
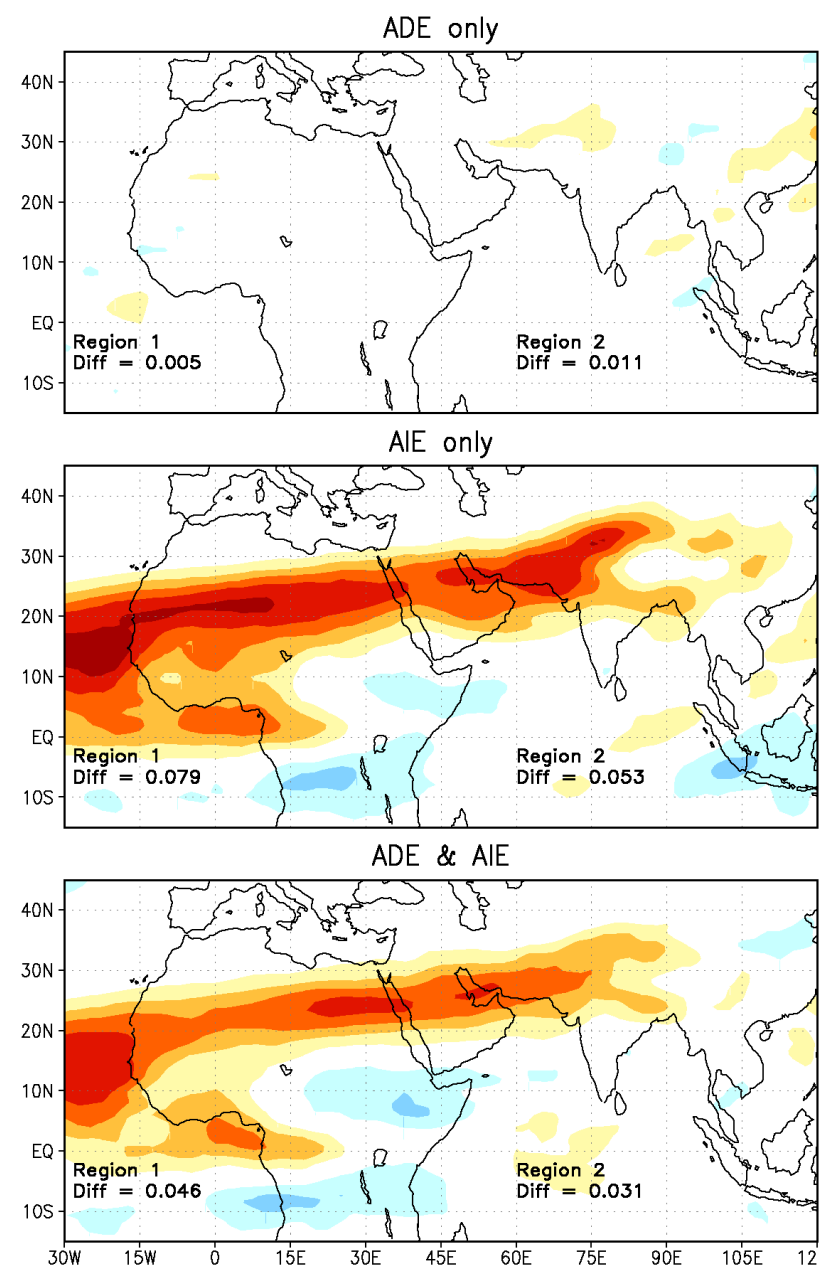

Column Cloud Fraction difference

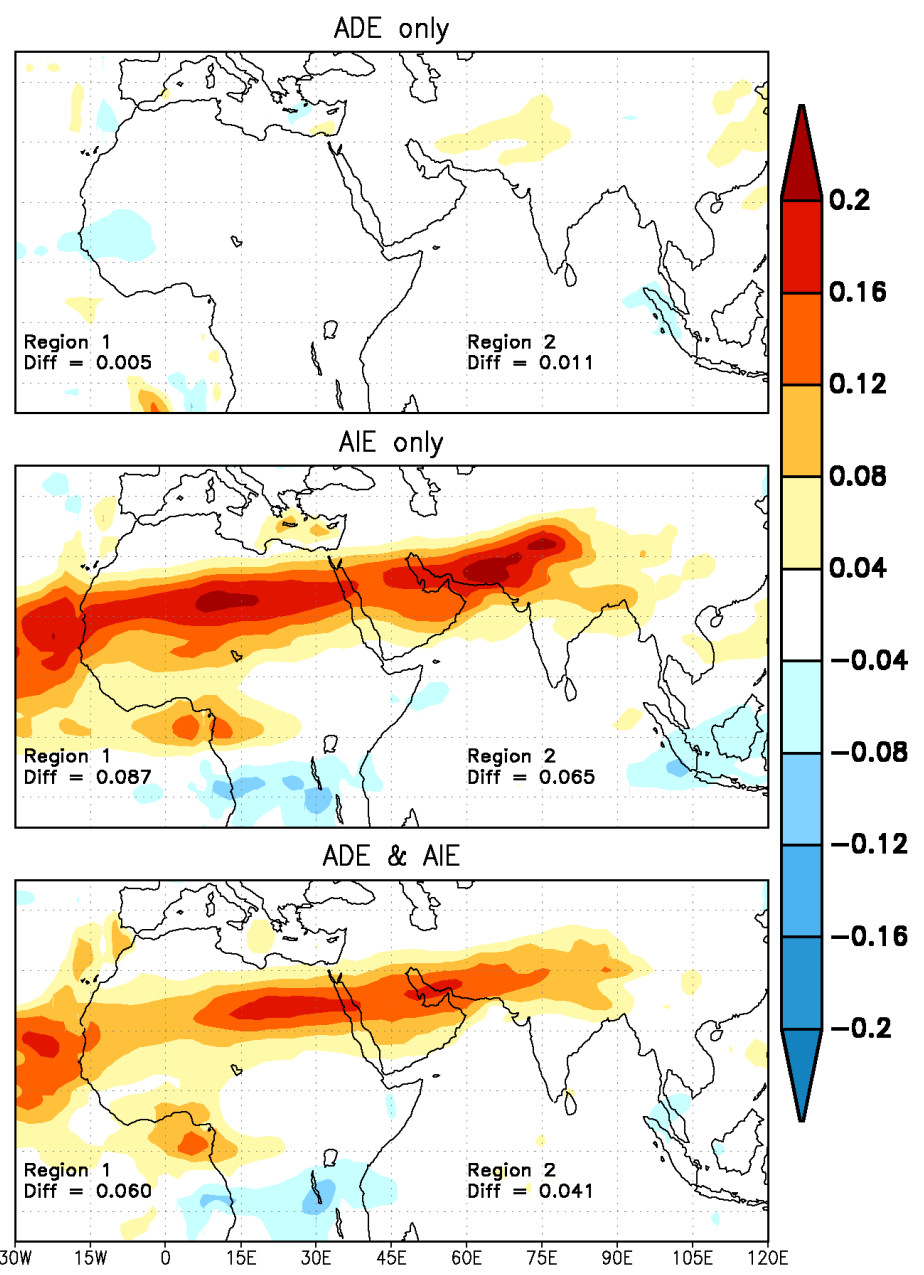

Fig. 7b. Same as Fig. 6 but for high (left) and all column (right) cloud fractions.

effect on the longwave escaping to space; which is an AIE influence. We reiterate that the increase in high-level clouds is not an outcome of local aerosols; it is the result of aerosol and water vapor entrainment and subsequent deployment of aerosols as CCN/IN for clouds and precipitation in the convective plumes; in fact, both aerosols and water vapor are entrained at all levels traversed by the moist convective towers and the condensing water vapor work interactively to form cloud particles that micro physically convert into precipitation. Thus the persistent cirrus clouds simulated at high levels were an outcome of more aerosols activated as CCN/IN causing more CPNC, inefficient precipitation microphysics, and increased life-time of detrained cloudy anvils. Accordingly, AIE of high clouds dominated the longwave anomaly at the top of the atmosphere.

\subsubsection{Surface and TOA net radiation anomalies}

The apportionment of net radiation between the ADE and AIE over Africa is quite different from that of India. At the surface, AIE makes a larger percentage of the total aerosol influence (Fig. 8). This shows that cloud effect on solar transmission at the surface exert a dominant role on the overall outcome. The changes in the net radiation at the top of the atmosphere (TOA) again shows the AIE influence dominate the overall outcome over India but not over Africa wherein there is strong warming by net radiation. The ADE on the TOA net radiation was rather small. This is consistent with Lau et al. (2009a) who also show that TOA net radiation does not change substantially. Due to the aerosol albedo, the net shortwave into the atmosphere reduces, whereas the longwave absorption is mitigated by shortwave cooling. Therefore, the net radiation changes due to ADE were small for both Africa and India. Employing series of single column model simulations, Lau et al. (2009c) show that 


\section{Sfc Net Radiation difference $\left(W \mathrm{~m}^{-2}\right)$}
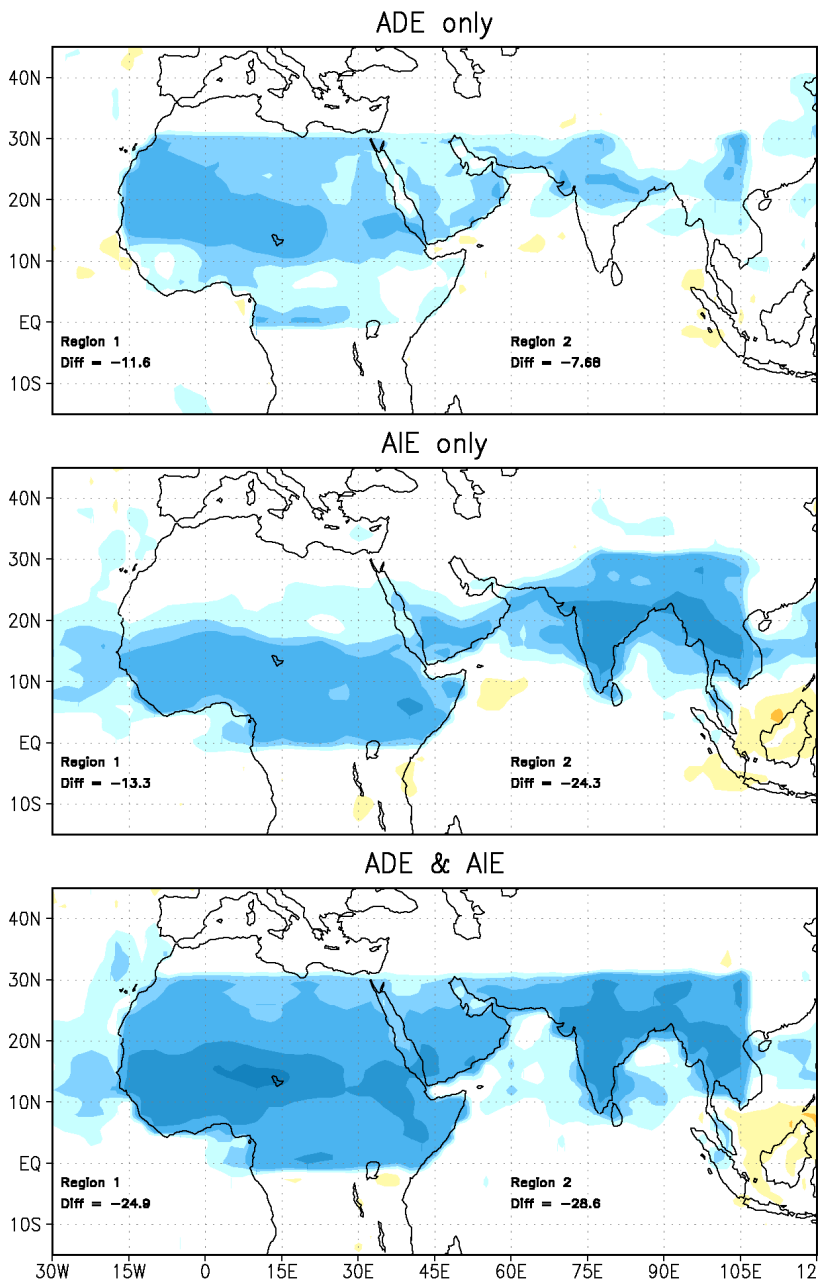

\section{TOA Net Radiation difference $\left(W \mathrm{~m}^{-2}\right)$}

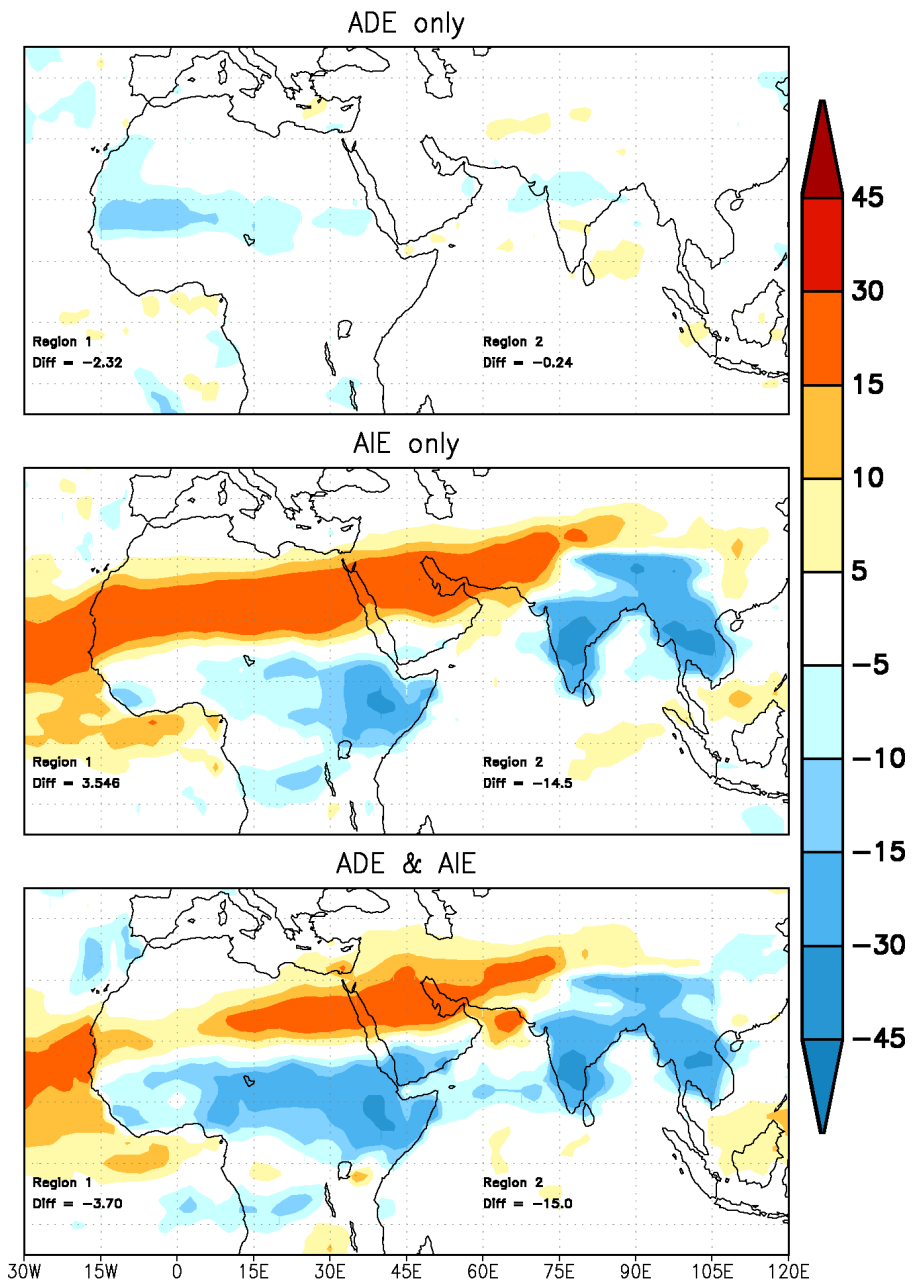

Fig. 8. Same as Fig. 6 but for fluxes of net radiation in $\mathrm{W} \mathrm{m}^{-2}$ at the surface (left) TOA (right).

longwave attenuations are small for aerosol with co-albedo $\left(1-\omega_{0}\right)<0.05$. Thus for Africa and India, TOA long and short wave radiation fluxes are significantly affected by the cloud life cycle(s) modulated by the AIE. An increase in TOA net radiation north of Sahel, i.e., over subtropical Africa, showed increased cloud optical thickness and invigorated AIE. The $\mathrm{ADE}$, on the other hand, is affected by the concentration of dust aerosols; its influence on increased shortwave reflection at TOA is mitigated by reduced longwave emission to yield a smaller net TOA radiation anomaly. Similarly, TOA net radiation reduces over northern India with roughly the same overall effect.

\subsubsection{Wind anomalies at 700 and $300 \mathrm{hPa}$}

Figure 9 shows wind vector anomalies and their statistical significance; we note that the most significant difference occur in areas of large wind anomalies. Wind anomalies simu- lated in AI experiments reveal that circulation anomalies extend far beyond the regions of prescribed aerosol anomalies. These could not be correctly inferred in AR simulations as discussed in Sect. 4.1. At $700 \mathrm{hPa}$, (Fig. 9, bottom panel) the combined influences of ADE and AIE on wind field anomalies show weakening of monsoon circulation all the way to the Indian Ocean. Even though these wind-field anomalies are consistent with reduced precipitation, but they are not equal to the sum of ADE and AIE shown in the top and middle panels. This means either the non-linear interactions are so strong as to change the entire circulation patterns or there is high natural variability and consequently, the anomalies over India are not so meaningful. However, each of the panels for $700 \mathrm{hPa}$ winds shows large areas with statistically significant responses at $99 \%$ confidence level. This means that the present outcome is robust and the behavior is due to the non-linear interactions largely. For winds at $300 \mathrm{hPa}$ level, however, the ADE and AIE alone results must add up to the 
$700 \mathrm{hPa}$ Wind difference $\left(\mathrm{m} \mathrm{s}^{-1}\right)$
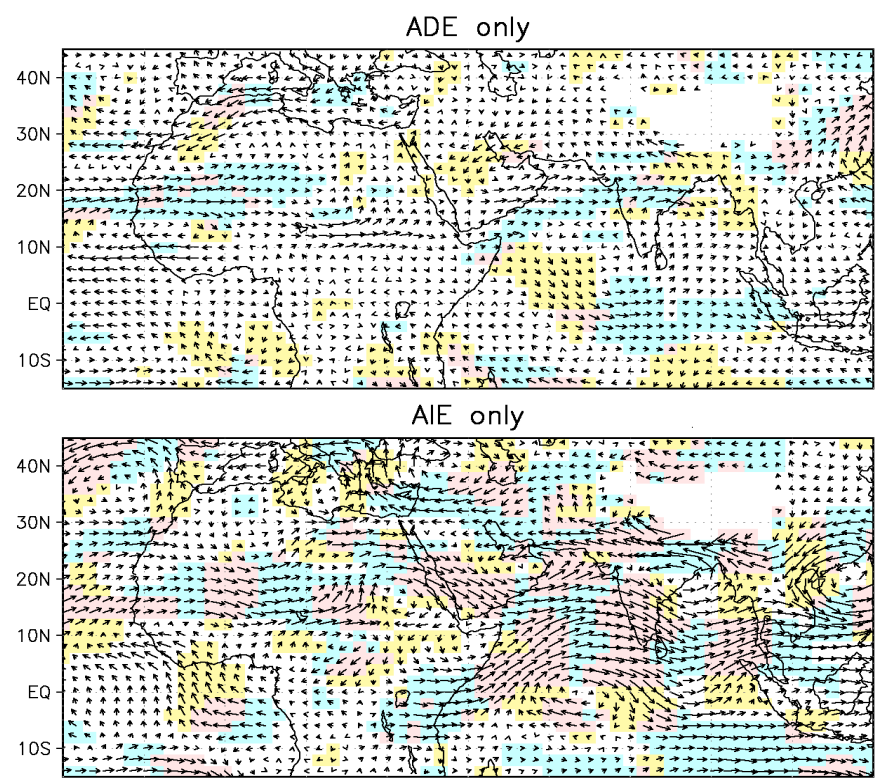

ADE \& AIE

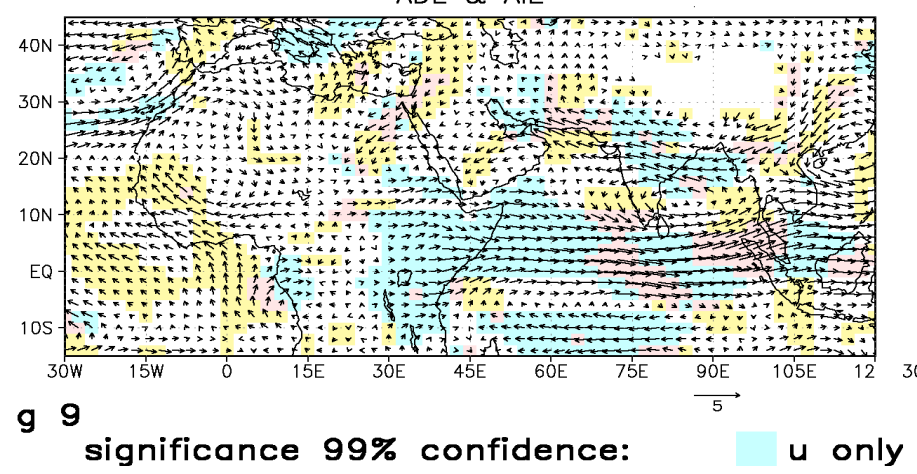

$300 \mathrm{hPa}$ Wind difference $\left(\mathrm{m} \mathrm{s}^{-1}\right)$

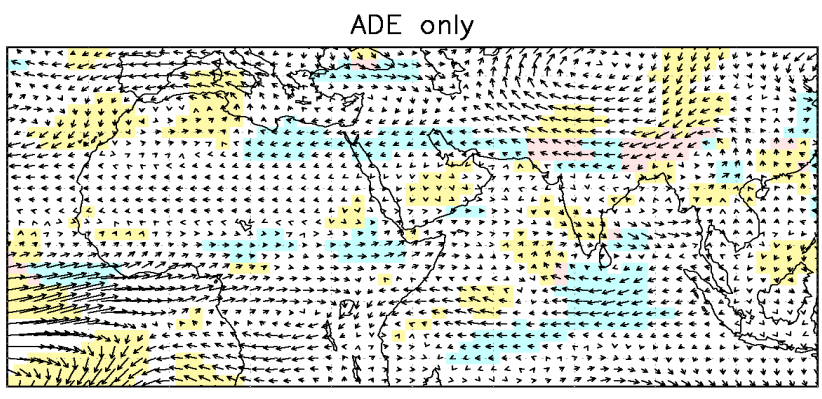

AIE only

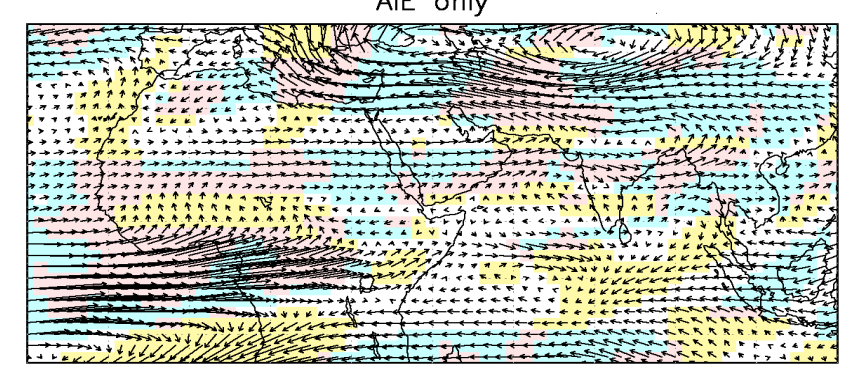

ADE \& AIE

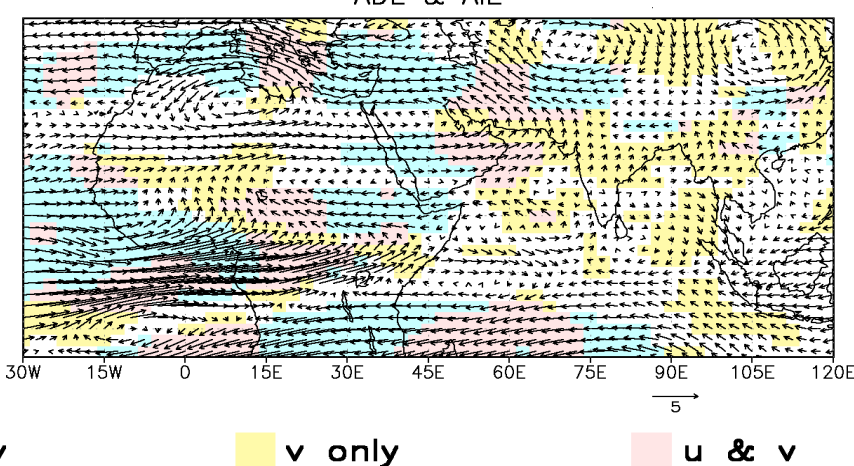

Fig. 9. Same as Fig. 6 but for the wind-vector differences at $700 \mathrm{hPa}$ (left) and $300 \mathrm{hPa}$ (right) and their statistical significance at $99 \%$ confidence level. Wind scales are displayed on the figures and statistical significance of the wind anomalies are color coded.

combined ADE and AIE simulations; but here too, there are regions where the superposition fails e.g., at the 30 degree latitudes of Indian region. However, in both regions and at both $700 \mathrm{hPa}$ and $300 \mathrm{hPa}$ levels, we see a larger influence of AIE over the ADE.

\section{Summary and discussions}

In recent years, the greenhouse gases have increased globally whereas the atmospheric aerosols have increased locally in selected regions; both are an outcome of burning fossil fuels and/or biomass. The Goddard Earth Observing System (GEOS-4) General Circulation Model (GCM) has AIE as an integral part of McRAS-AC, which enabled us to perform simulations for systematic evaluations of the direct and indirect effects of aerosols.
In the first set of simulations or baseline experiment, present day aerosols were used in the GCM. A six-member ensemble was produced in which each run started from the analyzed initial conditions for 1 May of six different years: 1982-1987, and was integrated through 31 August of the same year. Subsequently, the baseline simulations were used to make perturbations to initial conditions to compute the natural variability of the ensembles. Four more simulation studies were conducted to determine the influence of ADE and AIE on the circulation and precipitation of the four selected regions. Each study involved two sets of experiments; one set had $2 \mathrm{X}$ and one set with $1 / 2 \mathrm{X}$ climatological aerosols burden over the selected regions of India and Africa (current focus), as well as North and South America (companion paper). Allowing one month for initial adjustment, the JuneJuly-August (JJA) simulations were evaluated. In the first two experiments, the aerosol-anomaly regions were advectively restricted (AR) in one case and advectively interactive 
(AI) in the other case. Comparison of circulation, precipitation, and diabatic heating anomalies showed large discrepancies in the AR case(s); we infer that AR approximations are unrealistic for assessing the real world aerosol anomaly scenarios that operate essentially under essentially AI.

Two more experiments in which doubling of ADE and AIE were invoked one at a time showed that ADE and AIE work in concert to make the combined influences larger than each individual. Nevertheless, ADE and AIE impacts were vastly different over the Indian and African regions. This demonstrated the need to include both ADE and AIE simultaneously and interactively in climate simulations. Our results also showed that sub-continental scale aerosol anomalies potentially impact circulation and precipitation on the global scale.

The precipitation microphysics and cloud life-time, both of which are related to the AIE processes, were reasonably captured by McRAS-AC as was evidenced in the increased cloudiness and reduced solar radiation simulated at the surface (Kerminen et al., 2005). ADE mitigates the timeaveraged surface heating of the aerosol anomaly regions via the dimming effect of aerosol optical thickness (Ramanathan et al., 2005). Whereas the influence of ADE on the atmospheric dynamics of the selected tropical regions was addressed by Lau et al. (2009a) who showed how aerosols affect the vertical stability of the atmosphere and its dependent EHP mechanism as one of the key players of the ADE response. Our simulations showed complimentary roles of $\mathrm{ADE}$ and AIE for influencing the climate change.

As to the potential of ADE and AIE to mitigate the $\mathrm{CO}_{2}$ induced global warming, there are no simple answers. Whereas $\mathrm{ADE}$ and AIE would cool the near-surface temperatures, they also have the potential to produce unwarranted changes in the diabatic forcing of the global water cycle. Lau et al. (2006, 2009c) examined the ADE influences the Indian and African monsoon rainfall distributions. Recently, Zeng et al. (2009) inferred that increasing aerosols and associated IN would increase high-level cirrus that that is consistent with our simulations. If the finding to uphold, increasing aerosol effects would potentially offset some cirrus thinning by the deeper moist convection simulated in a doubled $\mathrm{CO}_{2}$ environment (Sud et al., 2008). Nevertheless, there is a need to better understand the behavior of the aerosol induced changes in circulation, vertical stability, and precipitation before we can address the complexities of aerosol mitigation of global warming. Whereas water clouds are much better understood, complexities of nucleation of ice clouds still have unresolved problems. To date, it remains a topic of intense laboratory and field experiments. Hence nucleation of ice-clouds is a major obstacle for realistic parametrization AIE. However, in comparing results of AIE and ADE acting individually as well as jointly, sum of their individual influences is less than the joint influences. This suggests significant non-linear physical and dynamical interactions between the ADE and the AIE.
The results of the ADE and AIE on JJA climate of selected anomaly regions of Africa and India depend on the specification of the radiative and nucleation properties of aerosols, as well as microphysics parameterization of precipitation efficiency. A rigorous evaluation and testing of these findings in different models and validation of the feedback processes such as espoused by Bony et al. (2006) may be necessary to reduce the model-dependency of the present findings. Assuming that some of our inferences above are model dependent, we argue that the simulated responses reported here align well with the known behavior of the aerosol physics used in the parameterization of AIE and ADE. Nevertheless, the importance of large aerosol anomalies at the subcontinental scales that are seen in the observations data is expected to be a subject of extensive research for determining its influence on the circulation and precipitation locally as well as globally. A comprehensive model intercomparison exercise in future may shed more light on the extent of model-dependence of the inferences of this study.

Acknowledgements. Almost all the authors affiliate with NASA/GFSC were funded through NASA funding through MAP, IDS, and other proposals related to aerosol Cloud Interaction. Others are collaborators helping in the development of a realistic model of aerosol-cloud interaction and its application to global circulation, cloudiness and rainfall.

Topical Editor F. D'Andrea thanks two anonymous referees for their help in evaluating this paper.

\section{References}

Ackerman, A. S., van Zanten, M. C., Stevens, B., Savic-Jovcic, V., Bretherton, C. S., Chlond, A., Gloaz, J.-G., Jiang, H., Khairoutdinov, M., Krueger, S. K., Lewellen, D. C. Lock, A., Moeng, C.-H., Nakamura, K., Petters, M. D., Snider, J. R., Weinbrecht, S., and Zulauf, M.: Large-eddy simulations of a drizzling, stratocumulus-topped marine boundary layer, Mon. Weather Rev., 137, 3, doi:10.1175/2008MWR2582.1, 2009.

Albrecht, B. A.: Aerosols, Cloud Microphysics, and Fractional Cloudiness, Science, 245(1989), 1227-1230, 1989.

Andreae, M. O., Jones, C. D., and Cox, P. M.: Strong present-day aerosol cooling implies a hot future, Nature, 435(3671), 11871190, 2005.

Ångström, A.: On the Atmospheric Transmission of Sun Radiation and on Dust in the Air, Geografiska Annaler, 11, 156-166, 1929.

Bell, T. L., Rosenfeld, D., Kim, K.-M, Yoo, J.-M., Lee, M.-I., and Hahnenberger, M.: Midweek increase in U.S. summer rain and storm heights suggests air pollution invigorates rainstorms, J. Geophys. Res., 113, D02209, doi:10.1029/2007JD008623, 2008.

Bollasina, M., Nigam, S., and Lau, K.-M.: Absorbing aerosols and summer monsoon evolution over south Asia: an observational portrayal, J. Climate, 21, 3221-3229, 2008.

Bony, S., Coleman, R., and Kattsov, V. M.: How well do we understand and evaluate climate change feedback processes. A Review Paper, J. Climate, 19, 3455-3482, 2006.

Brierley, C. M., Fedorov, A. V., Liu, Z., Herbert, T. D., Lawrence, K. T., and LaRiviere, J. P.: Greatly Expanded 
Tropical Warm Pool and Weakened Hadley Circulation in the Early Pliocene (27 March 2009), Science, 323(5922), 1714, doi:10.1126/science.1167625, 2009.

Chand, D., Wood, R., Anderson, T. L., Satheesh, S. K., and Charlson, R. J.: Satellite-derived direct radiative effect of aerosols dependent on cloud cover, Nature Geosci., 2, 181-184, 2009.

Charlson, R. J., Schwartz, S. E., Hales, J. M., Cess, R. D., Coakley Jr., J. A., Hansen, J.E., and Hoffman, D. J.: Climate Forcing by Anthropogenic Aerosols, Science, 255, 423-430, 1992.

Chin, M., Ginuox, P., Kinne, S., Torres, O., Holben, B. N., Duncan, B. N., Martin, R. V., Logan, J. A., Higurashi, A., and Nakijima, T.: Tropospheric Aerosol Optical Thickness from the GOCART Model and Comparisons with Satellite and Sun Photometer Measurements, J. Atmos. Sci., 59, 461-483, 2002.

Chin, M., Chu, D. A., Levy, R., Remer, L., Kaufman, Y., Holben, B. N., Eck, T., Ginoux, P., and Gao, Q.: Aerosol distribution in the Northern Hemisphere during ACE-Asia: Results from global model, satellite observations, and Sun photometer measurements, J. Geophys. Res., 109(D23), S90, doi:10.1029/2004JD004829, 2004.

Chou, M.-D. and Suarez, M. J.: An efficient thermal infrared radiation parameterization for use in general circulation models, NASA Tech. Memo., 104606, vol. 3, 85 pp., NTIS N95-15745, 1994.

Chou, M. D. and Suarez, M. J.: A Solar Radiation Parameterization for Atmospheric Studies, NASA Tech. Memo., 104606, vol. 15, 38 pp, 1999.

Chou, M. D., Suarez, M. J., Ho, C. H., Yan, M. H., and Lee, K. T.: Parameterizations for cloud overlapping and shortwave single scattering properties for use in general circulation and cloud ensemble models, J. Climate, 11, 202-214, 1998.

Chylek, P., Dubey, M. K., Lohmann, U., Ramanathan, V., Kaufman, Y., Lesins, G., Hudson, J., Altmann, G., and Olsen, S.: Aerosol indirect effect over the Indian Ocean, Geophys. Res. Lett., 33, L06806, doi:10.1029/2005GL025397, 2006.

Del Genio, A. D., Yao, M.-S., and Jonas, J.: Will moist convection be stronger in a warmer climate?, Geophys. Res. Lett., 34, L16703, doi:10.1029/2007GL030525, 2007.

Easter, R. C., Ghan, S. J., Zhang, Y., et al.: MIRAGE: Model description and evaluation of aerosols and trace gases, J. Geophys. Res.-Atmos., 109, D20210, doi:10.1029/2004JD004571, 2004.

Fountoukis, C. and Nenes, A.: Continued development of a cloud droplet formation parameterization for global climate models, J. Geophys. Res.-Atmos., 110, D11212, doi:10.1029/2004JD005591, 2005.

George, J. P., Harenduprakash, L., and Mohan, M.: Multi year changes of Aerosol Optical Depth in the monsoon region of the Indian Ocean since 1986 as seen in the AVHRR and TOMS data, Ann. Geophys., 26, 7-11, 2008,

http://www.ann-geophys.net/26/7/2008/.

Ginoux, P., Chin, M., Tegan, I., Prospero, J., Holben, B. N., Dubovik, O., and Lin, S. J.: Sources and distributions of dust aerosols simulated with the GOCART model, J. Geophys. Res., 106, 20225-20273, 2001.

Girolamo, L., Bond, T. C., Bramer, D., Diner, D. J. Fettinger, F., Kahn, R. A., Martonchik, J. V., Ramana, M., Ramanathan, V., and Rasch, P. J.: Analysis of Multi-angle Imaging Spectroradiometer (MISR) aerosol optical depths over greater India during winter 2001-2004, Geophys. Res. Lett., 31, L23115,
doi:10.1029/2004GL021273, 2004.

Gradel, T. E. and Crutzen, P. J.: Atmospheric Change: an Earth System Perspective, W. H. Freeman \& Co., New York, 1993.

Hansen, J., Sato, M., and Ruedy, R.: Radiative forcing and climate response, J. Geophys. Res., 102, 6831-6864, 1997.

Held, I. M. and Soden, B. J.: Robust responses of the hydrological cycle to global warming, J. Climate, 19(21), 5686-5699, 2006.

Hill, J., Stellmes, M., Udelhoven, Th., Röder, A., and Sommer, S.: Remote Sensing Department, FB VI Geography/Geosciences, University of Trier, Campus II, 54286 Trier, Germany, 1998.

Hobbs, P. V.: Effects of Aerosols on Clouds and Radiation, in: Global Energy and Water Cycles, edited by: Browning, K. A. and Gurney, R. J., p. 91-99, Camb. Univ. Press., 1999.

Huang, J., Zhang, C., and Prospero, J. M.: Large-scale effects of African aerosol on precipitation of the West African monsoon, Q. J. Roy. Meteorol. Soc., 13, 581-594, doi:10.1002/qj.391, 2009.

$\mathrm{Hu}, \mathrm{Y}$. and Fu, Q.: Observed poleward expansion of the Hadley circulation since 1979, Atmos. Chem. Phys., 7, 5229-5236, 2007, http://www.atmos-chem-phys.net/7/5229/2007/.

Hulme, M., Osborn, T. J., and Johns, T. C.: Precipitation sensitivity to global warming: comparisons of observations with HadCM2 simulations, Geophys. Res. Lett., 25(17), 3379-3382 (R), 1998.

IPCC: Climate Change 2007: The Physical Science Basis, Contribution of Working Group I to the Fourth Assessment Report of the Intergovernmental Panel on Climate Change, edited by: Solomon, S., Qin, D., Manning, M., Chen, Z., Marquis, M. C., Avery, K. B., Tignor, M., and Miller, H. L., Cambridge University Press, Cambridge, United Kingdom and New York, NY, USA, 2007.

Kalnay, E., Kanamitsu, M., and Kistler, R.: The NCEP/NCAR 40year reanalysis project, B. Am. Meteorol. Soc., 77(3), 437-471, 1996.

Kimberly, A., Prather, C. D., Hatch, and Grassian, V. H.: Analysis of Atmospheric Aerosols, Annu. Rev. Analyt. Chem., 1, 485514, 2008.

Kerminen, V. M., Lihavainen, H., Komppula, M., Viisanen, Y., and Kulmala, M.: Direct observational evidence linking atmospheric aerosol formation and cloud droplet activation, Geophys. Res. Lett., 32, L14803, doi:10.1029/2005GL023130, 2005.

Khvorostyanov, V. I. and Curry, J. A.: Toward the theory of stochastic condensation in clouds. Part I: a general kinetic equation, J. Atmos. Sci., 56, 3985-3996, 1999a.

Khvorostyanov, V. I. and Curry, J. A.: Toward the theory of stochastic condensation in clouds. Part II: analytical solutions of the gamma-distribution type, J. Atmos. Sci., 56, 3997-4013, 1999b.

Kiehl, J. T., Hack, J. J., Bonan, G. B., Boville, B. A., Briegleb, B. P., Williamson, D. L., and Rasch, P. J.: Description of the NCAR Community Climate Model (CCM3). NCAR/TN-420+STR, 152 pp. (available from NCAR, Boulder, CO 80307), 1996.

Kiehl, J. T., Hack, J. J., Bonan, G. B., Boville, B. A., Williamson, D. L., and Rasch, P. J.: The National Center for Atmospheric Research Community Climate Model: CCM3, J. Climate, 11, 1131-1149, 1998.

Kim, M. K., Lau, K. M., Chin, M., Kim, K. M., Sud, Y. C., and Walker, G. K.: Atmospheric teleconnection over Eurasia induced by aerosol radiative forcing during boreal spring, J. Climate, 19, 4700-4718, 2006.

Knox, E. G.: Atmospheric pollutants and mortalities in English local authority areas, J. Epidemiol. Community Health, 62, 442- 
447, 2008.

Krishnamurti, T. N., Chakraborty, A., Martin, A., Lau, W. K., Kim, K.-M., Sud, Y., and Walker, G.: Impact of Arabian Sea Pollution on the Bay of Bengal Winter Monsoon Rains, J. Geophys. Res., Atmosphere, 114, D06213, doi:10.1029/2008JD010679, 2009.

Lau, K.-M., Kim, M. K., and Kim, K. M.: Asian Summer Monsoon Anomalies Induced by Aerosol Direct Forcing: the Role of the Tibetan Plateau, Clim. Dynam., 7-8, 26, doi:10.1007/s00382006-0114-z, 2006.

Lau, K.-M. and. Kim, K.-M: Does aerosol weaken or strengthen the Asian monsoon? Mountains Witnesses of Global ChangesResearch in the Himalaya and Karakoram: Share-Asia Project, edited by: Baudo, R., Tartari, G., and Vuillermoz, E., Elsevier, pp. 13-22, 2007.

Lau, K.-M., Kim, K.-M., Sud, Y. C., and Walker, G. K.: A GCM study of responses of the atmospheric water cycle of West Africa and Atlantic to Saharan dust radiative forcing, Ann. Geophys., in review, 2009a.

Lau, K.-M., Kim, K.-M., Hsu, C. N., and Holben, B. N.: Possible influences of air pollution, dust-, and sandstorms on the Indian monsoon, WMO Bulletin, 58(1), 22-30, 2009b.

Lau, K. M., Kim, K. M., Sud, Y. C., and Walker, G. K.: Influence of aerosol - radiative forcings on the diurnal and seasonal cycles of rainfall over West Africa and Eastern Atlantic Ocean using GCM simulations, Clim. Dynam., accepted, 2009c.

Lin, S.-J.: A "vertically Lagrangian” finite-volume dynamical core for global models, Mon. Weather Rev., 132(10), 2293-2307, 2004.

Lin, S.-J. and Rood, R. B.: Multidimensional flux-form semiLagrangian transport schemes, Mon. Weather Rev., 124(9), 2046-2070, 1996.

Liu, X. and Penner, J. E.: Ice nucleation parameterization for global models, Meteorol. Z., 14(4), 499-514, 2005.

Liu, J., Xia, X., Wang, P., Zheng, Z., Li, Y., Cribb, M., and Chen, H.: Significant aerosol direct radiative effects during a pollution episode in northern China, Geophys. Res. Lett., 34, L23808, doi:10.1029/2007GL030953, 2007.

Lohmann, U. and Feichter, J.: Can the Direct and Semi-Direct Aerosol Effect Compete with the Indirect Effect on a Global Scale?, Geophys. Res. Lett., 28(1), 159-161, 2001.

Massie S. T., Torres, O., and Smith, S. J.: Total Ozone Mapping Spectrometer (TOMS) observations of increases in Asian aerosol in winter from 1979 to 2000, J. Geophys. Res., 109, D18211, doi:10.1029/2004JD004620, 2004.

Meehl, G. A., Arblaster, J. M., and Collins W. D.: Effects of black carbon aerosols on the Indian monsoon, J. Climate, 21, 28692882, 2008.

Menon, S., Hansen, J., Nazarenko, L. and Luo, Y.: Climate effects of black carbon aerosols in China and India, Science, 297, 22502253, 2002.

Myhre, G., Stordal, F., Johnsrud, M., Kaufman, Y. J., Rosenfeld, D., Storelvmo, T., Kristjansson, J. E., Berntsen, T. K., Myhre, A., and Isaksen, I. S. A.: Aerosol-cloud interaction inferred from MODIS satellite data and global aerosol models, Atmos. Chem. Phys., 7, 3081-3101, 2007, http://www.atmos-chem-phys.net/7/3081/2007/.

Nakajima, T.: Tropospheric Aerosol Optical Thickness from the GOCART Model and Comparisons with Satellite and Sun Photometer Measurements., J. Atmos. Sci., 59, 461-483, 2002.
Nakajima, T., Yoon, S.-C., Ramanathan, V., et al.: Overview of the Atmospheric Brown Cloud East Asian Regional Experiment 2005 and a study of the aerosol direct radiative forcing in east Asia, J. Geophys. Res., 112, D24S91, doi:10.1029/2007JD009009, 2007.

Nenes, A. and Seinfeld, J. H.: Parameterization of cloud droplet formation in global climate models, J. Geophys. Res.-Atmos., 108, 4415, doi:10.1029/2002JD002911, 2003.

Podgorny, I. A. and Ramanathan, V.: A modeling study of the direct effect of aerosols over the tropical Indian Ocean, J. Geophys. Res., 106, 24097-24105, 2001.

Prasad, A. K., Singh, R. P., and Singh, A.: Variability of aerosol optical depth over Indian subcontinent using MODIS data, J. Indian Soc. Rem. Sens., 32(4), 313-316, 2004.

Ramanathan, V., Crutzen, P. J., Kiehl, T. J., and Rosenfeld, D.: Aerosols, climate and the hydrological cycle, Science, 294, 2119-2124, 2001.

Ramanathan, V., Chung, C., Kim, D., Bettge, T., Buja, L., Kiehl, J. T., Washington, W. M., Fu, Q., Sikka, D. R., and Wild, M.: Atmospheric brown clouds: Impacts on South Asian climate and hydrological cycle, Proc. Natl. Acad. Sci. USA, 102, 5326-5333, 2005.

Ramanathan V. and Ramana, M. V.: Persistent, widespread, and strongly absorbing haze over the Himalayan foothills and the Indo-Gangetic Plains, Pure Appl. Geophys., 162, 1609-1626, 2005.

Reynolds, R. W., Rayner, N. A., Smith, T. M., Stokes, D. C., and Wang, W.: An Improved In Situ and Satellite SST Analysis for Climate, J. Climate, 15, 1609-1625, 2002.

Renaud, F. B. J., Dun, O., and Warner, K.: Control, Adapt, or Flee: How to face environmental migration?, Inter Sections No. 5/7, United Nations University Institute for Environment and $\mathrm{Hu}-$ man Security (UNU-EHS), Bonn, available at www.ehs.unu.edu, 2007.

Rosenfeld, D.: Suppression of rain and snow by urban and industrial air pollution, Science, 287, 1793-1796, 2000.

Satheesh, S. K. and Ramanathan, V.: Large difference in tropical aerosol forcing at the top of the atmosphere and Earth's surface, Nature, 405, 60-63, 2000.

Satheesh, S. K., Moorthy, K. K., Babu, S. S., Vinoj, V., and Dutt, C. B. S.: Climate implications of large warming by elevated aerosol over India, Geophys. Res. Lett., 35, L19809, doi:10.1029/2008GL034944, 2008.

Sato, M., Hansen, J., Koch, D., Lacis, A., Ruedy, R., Dubrovik, O., Holben, B., Chin, M., and Novakov, T.: Global Atmospheric Black Carbon Inferred from Aeronet, Proceedings of the National Academy of Sciences, 2003.

Seifert, A. and Beheng, K. D.: A double-moment parameterization for simulating autoconversion, accretion and self collection, Atmos. Res., 59, 265-281, 2001.

Shindell, D. and Faluveg, G.: Climate response to regional radiative forcing during the twentieth century, Nature Geoscience, 2, 294 300, doi:10.1038/ngeo473, 2009.

Simkhovich, B. Z., Kleinman, M. T., and Kloner, R. A.: Air Pollution and Cardiovascular Injury Epidemiology, Toxicology, and Mechanisms, J. Am. Coll. Cardiol., 52, 719-726, doi:10.1016/j.jacc.2008.05.029, 2008.

Sud, Y. C. and Lee, D.: Parameterization of aerosol indirect effect to complement McRAS cloud scheme and its evaluation with the 3- 
year ARM-SGP analyzed data for single column models, Atmos. Res., 86, 105-125, 2007.

Sud, Y. C., Mocko, D. M., and Lin, S.-J.: Performance of two cloudradiation parameterization schemes in the fvGCM for anomalously wet May and June 2003 over the continental United States and Amazonia, J. Geophys. Res. Atmos., 111(D6), 6201, doi:10.1029/2005JD006246, 2006.

Sud, Y. C. and Walker, G. K.: Microphysics of clouds with the relaxed Arakawa-Schubert scheme (McRAS). Part I: Design and evaluation with GATE phase III data, J. Atmos. Sci., 56, 31963220, 1999a.

Sud, Y. C. and Walker, G. K.: Microphysics of clouds with the relaxed Arakawa-Schubert scheme (McRAS). Part II: Implementation and performance in GEOS II GCM, J. Atmos. Sci., 56, 3221-3240, 1999b.

Sud, Y. C., Walker, G. K., and Lau, K. M.: Mechanisms regulating deep moist convection and sea-surface temperatures in the tropics, Geophys. Res. Lett., 26(8), 1019-1022, 1999c.

Sud, Y. C. and Walker, G. K.: New upgrades to the microphysics and thermodynamics of clouds in McRAS: SCM and GCM evaluation of simulation biases in GEOS GCM, Proc. Indian Nat. Sci. Acad., 69(5), 543-565, 2003.

Sud, Y. C. and Walker, G. K.: Influence of ice-phase physics of hydrometeors on moist-convection, Geophys. Res. Lett., 30, 1758, doi:10.1029/2003GL017587, 2004.

Sud, Y. C., Walker, G. K., Zhou, Y. P., Schmidt, G. A., Lau, K.-M., and Cahalan, R. F.: Effects of doubled CO2 on tropical sea surface temperatures (SSTs) for onset of deep convection and maximum SST: Simulations based inferences, Geophys. Res. Lett., 35, L12707, doi:10.1029/2008GL033872, 2008.
Takemura, T., Kaufman, Y. J., Remer, L. A., and Nakajima, T.: Two competing pathways of aerosol effects on cloud and precipitation formation, Geophys. Res. Lett., 34(4), L04802, doi:10.1029/2006GL028349, 2007.

Twomey, S.: The nuclei of natural cloud formation, II, The supersaturation in natural clouds and the variation of cloud droplet concentration, Geofis. Pura Appl., 43, 243-249, 1959.

Vecchi, G. A., Soden, B. J., Wittenberg, A. T., Held, I. M., Leetmaa, A., and Harrison, M. J.: Weakening of tropical Pacific atmospheric circulation due to anthropogenic forcing, Nature, 441(7089), 73-76, 2006.

Webster, P. J., Holland, G. J., Curry, J. A., and Chang, H.-R.: Changes in Tropical Cyclone Number, Duration, and Intensity in a Warming Environment, Science, 309(5742), 1844-1846, doi:10.1126/science.1116448, 2005.

Whitsel, E. A., Quibrera, P. M., Christ, S. L., Liao, D., Prineas, R. J., Anderson, G. L., and Heiss, G.: Heart Rate Variability, Ambient Particulate Matter Air Pollution, and Glucose Homeostasis: The Environmental Epidemiology of Arrhythmogenesis in the Women's Health Initiative, Am. J. Epidemiol., 169, 693703, 2009.

Wilcox, E. M., Sud, Y. C., and Walker, G. K.: Sensitivity of BorealSummer Circulation and Precipitation to Atmospheric Aerosols in Selected Regions - Part 2: The Americas, Ann. Geophys., 27, 4009-4021, 2009, http://www.ann-geophys.net/27/4009/2009/.

Zeng, X., Tao, W. K., Zhang, M., Hou, A. Y., Xie, S. C., Lang, S., Li, X.-W., Starr, D. O., and Li, X.-F.: A Contribution by ice nuclei to global warming, Q. J. Roy. Meteorol. Soc., 135, 643, doi:10.1002/qj.449, 2009. 